\title{
MAMÍFEROS QUATERNÁRIOS DA CAVIDADE ES-08, MUNICÍPIO DE PRUDENTE DE MORAIS, MINAS GERAIS: ANÁLISES TAFONÔMICA E TAXONÔMICA
}

\author{
ANDRÉ GOMIDE VASCONCELOS \\ Programa de Pós-Graduação em Geologia, UFMG, Av. Antônio Carlos 6627, 31270-901, Belo Horizonte, MG, Brasil. \\ andregomide86@gmail.com \\ KARIN ELISE BOHNS MEYER \& MARCOS SANTOS CAMPELLO \\ CPMTC e Departamento de Geologia, IGC/UFMG. Av. Antônio Carlos 6627, 31270-901, Belo Horizonte, MG, Brasil. \\ bohnsmeyer@yahoo.com.br,mscampello2005@yahoo.com.br
}

\begin{abstract}
QUATERNARY MAMMALS FROM ES-08 CAVE, PRUDENTE DE MORAIS MUNICIPALITY, MINAS GERAIS STATE: TAPHONOMIC AND TAXONOMIC ANALYSES. The work developed at the cave ES-08, localized in Escrivania's outcrop, at Prudente de Morais, MG, was done to understand: (i) the mechanisms of transport and sedimentation that contributed to mold the sedimentary deposit that consists of a fossiliferous carbonated soil; (ii) to identify taxonomically the bioclasts; (iii) to identify the taphonomic processes and their agents; and (iv) to propound a taphonomic method of collection of fossils preserved in carbonate matrix deposited in caves. Among the 191 bioclasts collected, 40 fossils were identified and attributed to the following taxa: Mylodontidae, Dasypus novemcinctus, Lagomorpha, Cuniculus major, Speothos sp., Eira barbara e Tayassu pecari. The taphonomic alterations observed in the fossils, the characteristics of the cave and of the deposit itself show that the fossiliferous sediment was deposited through the action of mudflow. The method adopted for the taphonomic collection was essential. Through this method we could rescue a high number of fossils in good conditions and observed how the bioclasts were arranged in the carbonate matrix, representing an unusual study on skeletal remains preserved in carbonated matrix in caves.
\end{abstract}

Key words: Lagoa Santa karst, Escrivânia limestone, in situ taphonomy, ex situ taphonomy.

RESUMO - São apresentados os resultados do estudo desenvolvido com material coletado na cavidade ES-08, inserida no maciço Escrivânia, Município de Prudente de Morais, MG. Tal estudo foi conduzido de forma a: (i) compreender os mecanismos de transporte e sedimentação atuantes para a formação do depósito sedimentar que consiste de um solo carbonatado suspenso (paleopiso) com fósseis; (ii) identificar taxonomicamente os restos de vertebrados coletados; (iii) relacionar as alterações tafonômicas com seus agentes causadores; e (iv) propor um método de coleta tafonômica para restos fósseis dispostos em solos carbonatados preservados em cavernas. Dentre os 191 bioclastos coletados, foram identificadas 40 peças, atribuídas aos seguintes táxons: Mylodontidae, Dasypus novemcinctus, Lagomorpha, Cuniculus major, Speothos sp., Eira barbara e Tayassu pecari. O índice MNI para se estimar o número de indivíduos preservados no depósito mostrou-se mais adequado. Através de observações das macrofeições tafonômicas impressas nos fósseis, como o estado de desarticulação e fragmentação dos ossos, de sua disposição caótica em meio a matriz, além de indicativos de fluxo hidráulico nos condutos da caverna, constatou-se que o depósito foi formado a partir de fluxos gravitacionais e trativos, com possíveis retrabalhamentos do sedimento. $\mathrm{O}$ método adotado para coleta (fragmentação controlada do paleopiso) foi fundamental, uma vez que através dele pôde-se resgatar um número expressivo de material e ainda se obter dados sobre a posição original dos fósseis, estudo incomum para fósseis preservados em matriz carbonatada inserida em cavernas.

Palavras-chave: carste de Lagoa Santa, maciço Escrivânia, tafonomia in situ, tafonomia ex situ.

\section{INTRODUÇÃO}

Dentre a fauna de vertebrados, os mamíferos constituem o grupo com melhor representatividade no registro fóssil do Quaternário e, por apresentar uma grande similaridade com a fauna atual, possibilita a realização de estudos taxonômicos, de relações ecológicas, reconstituição climática, dentre outros, com maior precisão (Cartelle \& Hartwing, 1996; Kellner \&
Campos, 1999; Bergqvist \& Almeida, 2004; Kraemer, 2005; Hubbe, 2008; Suguio, 2010).

No Brasil, diversos depósitos quaternários destacamse pela quantidade, e às vezes pela qualidade do material fóssil ali preservado (Kellner \& Campos, 1999). Dentre essas concentrações fossilíferas, destacam-se os depósitos fluviais na região Norte (e.g. Paula Couto, 1979; Cartelle, 1994; Holanda, 2007; Nascimento, 2008; Araújo-Júnior 
et al., 2012), as planícies costeiras, especialmente a do Rio Grande do Sul (e.g. Cartelle, 1994; Buchmann, 2002; Rodrigues et al., 2003), os tanques naturais, paleolagoas e lagoas intermitentes da região Nordeste (e.g. Brito, 1979; Paula Couto, 1979; Cartelle, 1994; Dantas \& Tasso, 2007; Riff et al., 2008; Ximenes, 2009; Araújo-Júnior et al., 2013) e as cavidades naturais inseridas principalmente em rochas carbonáticas, com registros para todas regiões do Brasil (e.g. Lund, 1836; Paula Couto, 1952; Brito, 1979; Paula Couto, 1979; Cartelle, 1992, 1994; Kellner \& Campos, 1999; Porpino et al. 2004; Sedor et al., 2004; Salles, 2006; Sedor \& Silva, 2006; Hubbe, 2008; Vasconcelos et al., 2008; Dantas, 2009; Cartelle, 2012; Missagia et al., 2012; Vasconcelos et al., 2012; Hsiou et al., 2013).

Segundo Bergqvist \& Almeida (2003), é nas cavernas que ocorre o maior número de achados fósseis de mamíferos no Brasil. Isso se deve a características peculiares que normalmente estão relacionadas ao ambiente cavernícola, como ausência de predadores, carniceiros e necrófagos, temperatura e umidade constantes, e ausência de incidência de luz solar, fatores estes que podem proporcionar uma melhor preservação de restos de animais, que adentram a cavidade, à procura de abrigo e/ou por queda acidental, quando mortos por transporte hidráulico, gravitacional ou ainda carregados por predadores (Lund, 1836, 1837; Simms, 1994).

A grande parte dos estudos envolvendo os fósseis coletados em cavernas dá ênfase a trabalhos taxonômicos (e.g. Lund, 1841; Winge, 1888, 1906; Ameghino, 1907; Krone, 1909; Paula Couto, 1979; Cartelle, 1992; Vasconcelos et al., 2008). Outros trabalhos se restringem a análises tafonômicas ex situ do material, onde não há estudos do depósito ou descrições detalhadas dos procedimentos adotados durante a coleta (e.g. Castro \& Langer, 2008; Donato et al., 2008; Perini et al., 2008). Além disso, tais estudos não são realizados de maneira completa devido à dificuldade de acesso e de preservação dos depósitos, ou pelo fato da coleta ter sido realizada por terceiros, sem o cuidado de realizar anotações sobre o depósito (e.g. Winge, 1906; Castro \& Langer, 2008; Vasconcelos et al., 2008; Langer et al., 2013). Assim, estudos que adotam o método de coleta tafonômica envolvendo restos atuais e paleontológicos de vertebrados em cavidades naturais no Brasil são escassos quando comparados aos trabalhos de cunho taxonômico (e.g. Lund, 1836; Barros et al., 1984; Almeida, 2000; Castro \& Langer, 2008; Hubbe, 2008; Ferreira et al., 2012; Hubbe \& Auler, 2012).

No contexto de estudos de fósseis coletados em cavidades outro aspecto que chama a atenção é a falta de utilização de métodos de datação, o que acarreta interpretações incompletas acerca dos paleoambientes, das extinções e amplitude estratigráfica dos fósseis (Piló, 1998; Piló et al., 2004; Auler et al., 2006; Hubbe, 2008; Hubbe \& Auler, 2012). A carência de estudos envolvendo idades absolutas dos fósseis coletados em cavernas pode estar relacionada ao fato de não haver material adequado para datação, como a presença de colágeno nos ossos, e/ou sedimentos com as características necessárias para se obter uma idade segura, onde grande parte dos depósitos químicos estão contaminados.
No presente trabalho são apresentados os resultados do estudo da cavidade ES-08, no maciço Escrivânia, município de Prudente de Morais, MG, com o objetivo de: (i) identificar os mecanismos de transporte e sedimentação atuantes para a formação do depósito sedimentar que consiste de um solo carbonatado suspenso (paleopiso) com fósseis; (ii) identificar taxonomicamente os restos de vertebrados coletados; (iii) descrever as características tafonômicas do depósito; (iv) relacionar as alterações tafonômicas com seus agentes causadores, e (v) propor um método de coleta tafonômica para restos fósseis dispostos no paleopiso.

\section{ÁREA DE ESTUDO}

O maciço que abriga a cavidade ES-08 está localizado a noroeste de Prudente de Morais, município situado a $65 \mathrm{~km}$ de Belo Horizonte, Minas Gerais. A região de estudo está inserida no contexto geológico do Grupo Bambuí e do Carste de Lagoa Santa, sendo este último famoso por abrigar inúmeras cavidades naturais, além de importantes sítios paleontológicos e arqueológicos (Kohler, 1989; Cartelle, 1994; Hubbe, 2008; Holten \& Sterll, 2011) (Figura 1).

\section{Aspectos geológicos e geomorfológicos}

A região do maciço Escrivânia está inserida no Planalto de Lagoa Santa, entre a Depressão de Vespasiano, ao Sul, o Planalto de Neves, a Sudoeste, e a Depressão de Sete Lagoas, a Norte, se estendendo até os contrafortes da Serra do Cipó. O Planalto de Lagoa Santa se desenvolve sobre filitos e carbonatos, cujas camadas sub-horizontais mergulham ligeiramente para Nordeste (Kohler, 1989).

O maciço Escrivânia apresenta aspectos geomorfológicos semelhantes a outras áreas da região cárstica de Lagoa Santa, caracterizadas pela ocorrência de maciços situados em grandes depressões, com as bordas posicionadas no nível ou mais elevadas que o topo dos maciços (Paula Couto, 1958) (Figura 2).

O maciço estudado é constituído por metassedimentos carbonáticos com alto metamorfismo e teores de carbonato de cálcio acima de $95 \%$. Estas rochas fazem parte da Formação Sete Lagoas, Grupo Bambuí e o maciço estão localizados no interfluvial entre o Ribeirão da Mata e Rio das Velhas (Kohler, 1994).

O Grupo Bambuí compreende rochas calcárias, ardosianas e filíticas, formadas em plataforma carbonática a aproximadamente $600 \mathrm{Ma}$, as quais ocupam a maior parte da bacia do São Francisco situada na porção Centro-Sul do Cráton do São Francisco (Souza Cunha, 1964; Alkmim \& Martins Neto, 2001).

O calcário do Grupo Bambuí na área do maciço Escrivânia tem granulometria fina e cor acinzentada. A espessura das camadas do calcário que abrigam as cavernas são centimétricas, dispostas em um acamamento horizontalizado, com um mergulho levemente para Leste. A maior parte do calcário presente na área apresenta uma baixa quantidade de magnésio e impurezas, característica que condiciona uma maior taxa de dissolução da rocha carbonática, proporcionando 


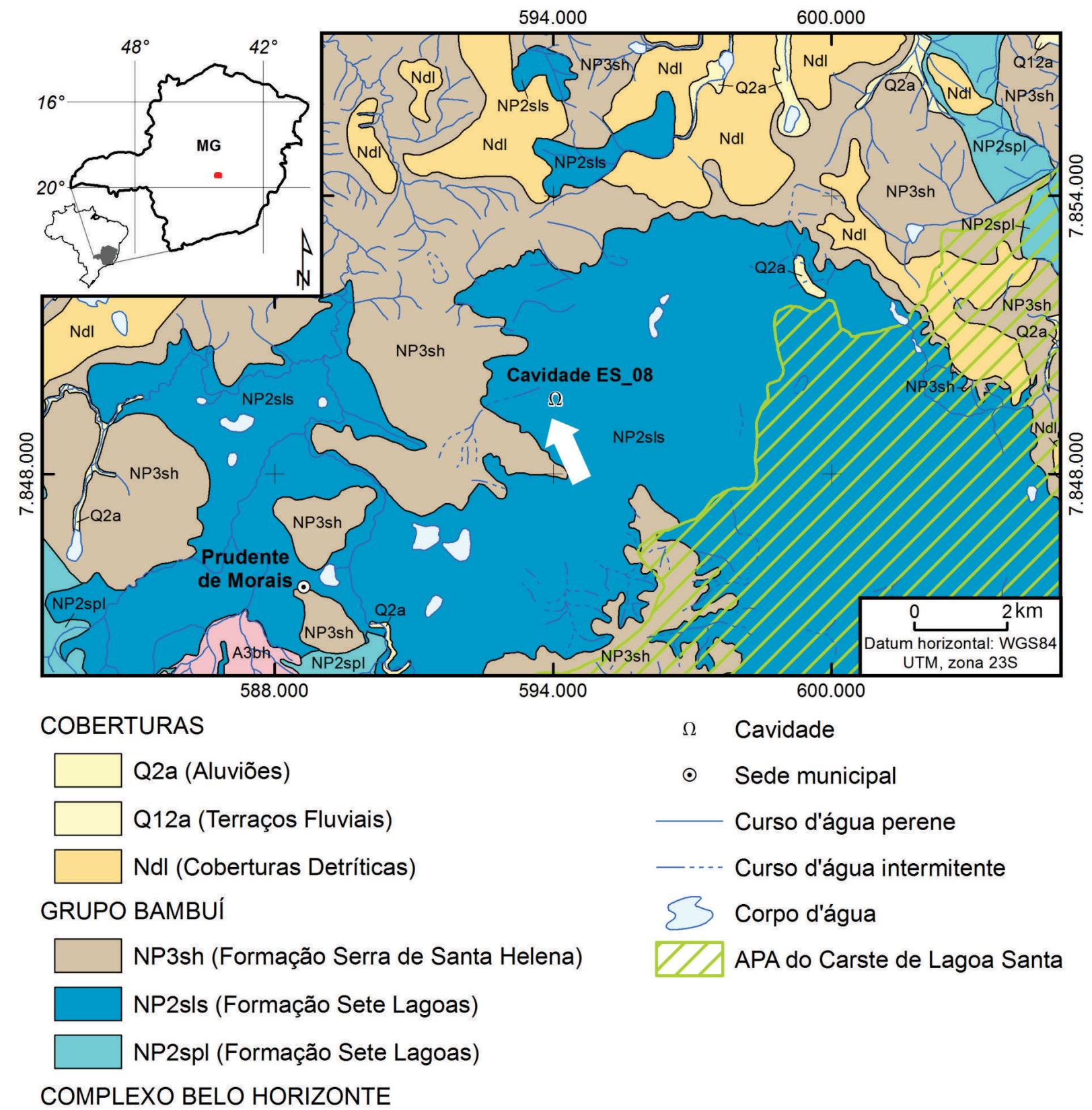

A3bh (Ortognaisses)

Figura 1. Mapa geológico da área de estudo e localização da cavidade ES-08 $(\Omega)$.

Figure 1. Geologic map of the studied area and location of the cave ES-08 $(\Omega)$.

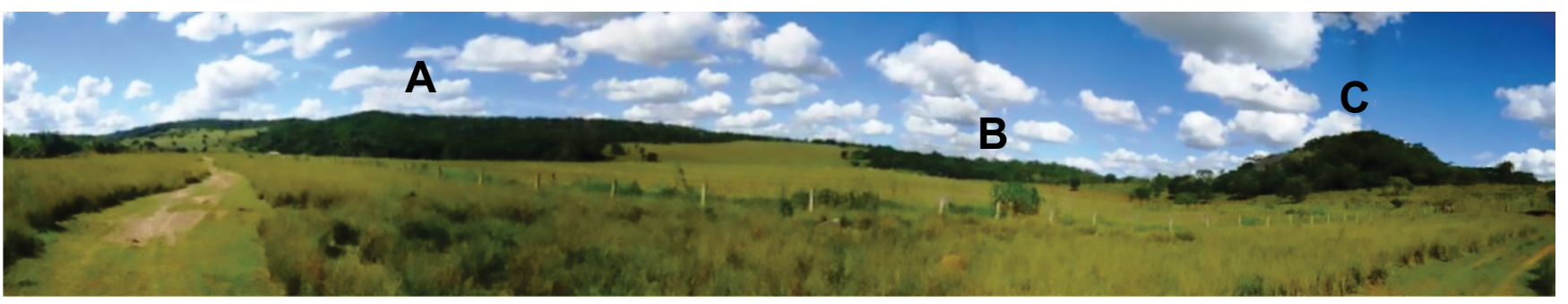

Figura 2. Vista da área de estudo. A, Maciço do Limeira; B, Maciço do Escrivânia; C, Maciço dos Ingleses.

Figure 2. View of the studied area. A, Limeira's outcrop; B, Escrivânia's outcrop; C, Ingleses' outcrop. 
ao carste da área de estudo um elevado grau de maturidade, fato confirmado pela grande quantidade de feições cársticas presentes na área, como dolinas, cavidades naturais (cavernas, abrigos e abismos), e canyons (Auler, 1994).

\section{MATERIAL E MÉTODOS}

\section{Escolha da cavidade para estudo}

Para a escolha da cavidade a ser estuda de modo detalhado, foi realizado um levantamento do potencial paleontológico das cavidades naturais (abismos, abrigos e cavernas) inseridas nos maciços calcários Escrivânia, Limeira e Ingleses, localizados a Noroeste da Área de Proteção Ambiental Carste de Lagoa Santa. O levantamento se baseou nos métodos propostos na Instrução Normativa $n^{\circ} 2$ (IN-02) e no termo de referência para elaboração de estudos de impacto ambiental para atividades minerárias em áreas cársticas no Estado de Minas Gerais da Fundação Estadual do Meio Ambiente (FEAM), de Minas Gerais (Minas Gerais, 2005; Brasil, 2009).

Embora outras cavidades da área, onde também foram recuperados fósseis para estudos posteriores, apresentassem um alto potencial paleontológico, as características como fácil acesso à cavidade e a presença de fósseis aflorando da matriz carbonática em posição estratigráfica inalterada e a localização do depósito, na qual permitiu sua retirada sem a necessidade de escavação em profundidade foram os fatores que determinaram a escolha da caverna ES-08 para este estudo.

\section{Análise tafonômica}

Este estudo foi conduzido de forma a identificar os mecanismos de transporte e sedimentação atuantes na formação do depósito sedimentar que consiste de um paleopiso com fósseis. A coleta controlada dos blocos do paleopiso para posterior retirada dos fósseis em laboratório e identificação de feições macroscópicas dos ossos que indicam os processos pelos quais passaram os ossos antes e durante $o$ processo deposicional consistiu no método empregado para o estudo tafonômico detalhado.

A coleta seguiu critérios tafonômicos adaptados de Holz \& Barberena (1989), Almeida (2000) e Holz \& Simões (2002), de modo que o solo carbonatado suspenso (paleopiso) foi fragmentado com o uso de marreta e cinzéis no interior da caverna para análise e retirada dos bioclastos em laboratório.

\section{Feições macroscópicas dos ossos}

Foram analisadas assinaturas tafonômicas macroscópicas dos ossos tais como alterações causadas por agentes biológicos, e físico-químicos, como intemperismo, transporte, retrabalhamento, bem como a representatividade óssea relacionada a cada táxon. A identificação e interpretações destas assinaturas macroscópicas seguiram métodos propostos por Hill (1988), Behrensmeyer (1991), Lyman (1994), Silva (2001), Beisaw (2013) e Mayer (2013).

As feições mais importantes observadas foram as alterações impressas que fogem ao padrão morfológico dos ossos, como a presença de ranhuras, sulcos, perfurações, desgastes acentuados, quebras e fraturas.
Foram observadas as seguintes características nos ossos: ontogenia (ossos de indivíduo jovem, adulto, senil); patologias (ossos que apresentaram alguma alteração morfológica como cicatriz ou calo ósseo); ações de animais, (indicadas pelas marcas de dentes de predadores/carniceiros ou de roedores); alterações causadas durante a coleta ou preparação do material (fraturas recentes, cortes, perfurações); permineralização (por sedimentos químicos e/ou clásticos); grau de fragmentação (categoria I: íntegro $>90 \%$; categoria II: parcialmente íntegro $89-50 \%$; categoria III: fragmentado $<50 \%$ ); abrasão (arestas arredondadas) e marcas de intemperismo.

Embora outras feições tafonômicas tenham sido analisadas, apenas foram citadas as modificações apresentadas em pelo menos um osso, assim, modificações como marcas antrópicas relacionadas a alimentação e confecção de artefatos, alterações causadas pelo fogo e pisoteio não estão relacionadas.

\section{Mecanismos de transporte e sedimentação do depósito}

Critérios para interpretações da formação de depósitos fossilíferos em cavernas, adotados por Almeida (2000), Piló et al. (2004), Castro \& Langer (2008), Hubbe (2008), Mayer (2011) e Hubbe \& Auler (2012) serviram de referência para a interpretação dos processos atuantes na formação do paleopiso fossilífero da cavidade ES-08, como a morfologia da caverna, localização das entradas e marcas de enchentes atuais e pretéritas. Já em relação ao próprio paleopiso, foram observadas feições de suas características gerais, como forma, volume e feições sedimentológicas da matriz.

\section{Coleta do paleopiso}

A primeira etapa da coleta dos blocos foi a demarcação de pontos fixos nas paredes Norte, Leste e no teto, que serviram de referência para nortear as distâncias em que cada fragmento do paleopiso se encontrava no conduto (Holz \& Barberena, 1989; Almeida, 2000; Holz \& Simões, 2002) (Figura 3).

As distâncias foram mensuradas a partir de uma demarcação

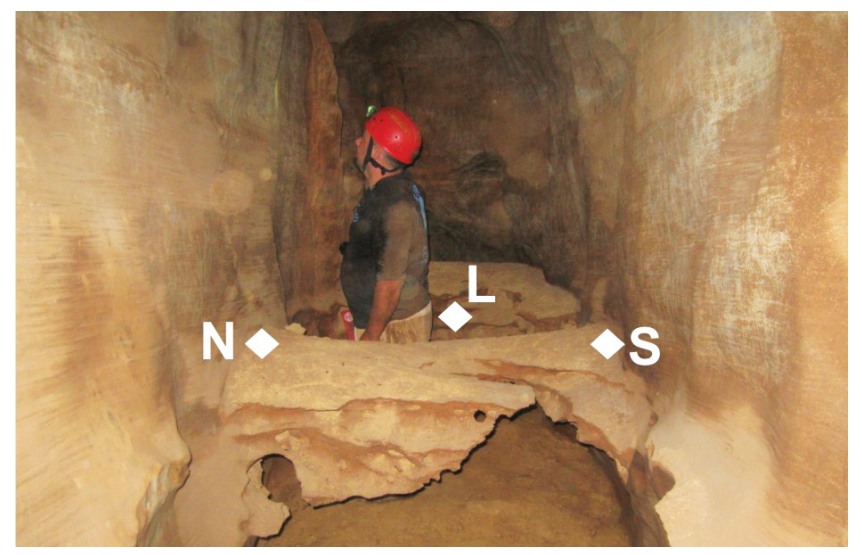

Figura 3. Detalhe do solo carbonatado (paleopiso) e localização dos pontos de referência utilizados para a remoção dos blocos do paleopiso. Abreviações: N, Norte; L, Leste; S, Sul.

Figure 3. Detail of carbonate matrix (hanging layer) and locations of the points used as reference to remove the hanging layer parts. Abbreviations: N, North; L, East; S, South. 
inserida em cada bloco antes de sua retirada do paleopiso. Esses pontos (pontos-controle) serviram como referência para posterior localização dos fósseis na matriz (Almeida, 2000).

Com a demarcação dos pontos nos blocos retirados da caverna, foi possível, mesmo com o paleopiso fragmentado, ter o posicionamento exato dos bioclastos no depósito, o que possibilitou a visualização de sua distribuição em planta e perfil do material coletado. Por possuírem frações friáveis, alguns blocos se desprenderam do paleopiso durante a coleta o que impossibilitou a identificação de sua posição original no paleopiso. Mesmo assim, todos os blocos foram recolhidos para preparação em laboratório, visando a verificação da ocorrência de fósseis preservados nestas porções desagregadas dos blocos.

O paleopiso foi fragmentado em 45 blocos, dos quais 36 apresentaram bioclastos preservados em seu interior. Uma tabela foi confeccionada baseada em Holz \& Barberena (1989), para anotações durante a coleta dos blocos do paleopiso. Nesta tabela estão discriminadas as informações mais relevantes para que nenhum dado seja perdido durante a coleta dos bioclastos contidos em cada bloco. As informações de localização do bloco são baseadas no ponto-controle e sua distância em relação aos pontos fixos no conduto. Em laboratório, a nova referência para a localização e direção dos fósseis foi o ponto-controle.

\section{Identificação taxonômica}

A identificação taxonômica do material foi realizada por meio de comparação direta com o material depositado nas coleções de Paleontologia e Mastozoologia do Museu de Ciências Naturais PUCMinas. A descrição anatômica dos ossos seguiu a descrita na Nomina Anatomica Veterinaria (International Committee on Veterinary Gross Anatomical Nomenclature, 1983).

Para a identificação de peças esqueletais como pertencentes a um mesmo indivíduo, foram utilizadas características como estágio ontogenético, ausência de repetição de peças esqueletais de mesma posição anatômica, peças quebradas que se uniam e características fossildiagenéticas compatíveis (Lyman, 1994; Sinbaldi, 2010). Os fósseis foram tombados na coleção de Paleontologia do Instituto de Geociências, da UFMG, sob os números IGC/0554 a IGC/0593.

\section{Índices de número mínimo de indivíduos de cada táxon (MNI) e número de espécimes identificados por táxon (NISP)}

O MNI e NISP são índices utilizados para se estimar a quantidade mínima de espécies (e espécimes) de um determinado depósito e se baseiam na contagem de ossos. $\mathrm{O}$ MNI é baseado na contagem das peças esqueletais homólogas da mesma espécie que mais se repetem, sendo que a partir desta contagem se determina ao número mínimo de indivíduos preservados em um determinado depósito. Já para o NISP é considerado que cada bioclasto pertence a um indivíduo diferente (Shipman, 1981; Badgley, 1986; Lyman, 1994).

Segundo Hubbe (2008), diferentes autores apresentam variados índices para se quantificar os bioclastos e os táxons presentes em um determinado depósito fossilífero a fim de se estabelecer qual seria o mais adequado para a realização deste procedimento tafonômico (Badgley, 1986; Lyman, 1994; Gilinsky \& Benningtn, 1994; Munro \& Bar-Oz, 2004).

Os índices MNI e NISP, quando aplicados de maneira conjunta, oferecem um panorama geral em relação à quantidade mínima e máxima de indivíduos preservados em um determinado depósito. Porém, são as características de formação do próprio depósito que vão indicar qual índice é o mais adequado de se aplicar. O MNI é mais indicado para depósitos formados a partir de pouco transporte e retrabalhamento, já depósitos que apontam uma alta energia envolvida em sua formação o índice NISP é mais adequado (Badgley, 1986; Castro \& Langer, 2008; Hubbe, 2008).

Neste sentido, para quantificar as espécies (e espécimes) coletadas na Caverna ES-08, foram utilizados os índices de abundância MNI (número mínimo de indivíduos de cada táxon) e NISP (número de espécimes identificados por táxon).

\section{RESULTADOS}

\section{Características gerais da área}

Dentre as 101 cavidades naturais visitadas na área prospectada, a cavidade ES-08 foi a que apresentou as melhores condições para realizar o estudo tafonômico detalhado, por apresentar alto potencial paleontológico com fósseis ainda inseridos nas camadas do paleopiso, ao contrário das demais cavidades que apresentavam material rolado e visivelmente transportado, não sendo possível a identificação das camadas sedimentares onde foram depositados.

Baseado em critérios descritos nos documentos FEAM (2005) e Brasil (2009), o potencial fossilífero apresentado pela cavidade ES-08 foi classificado como de alto potencial, por apresentar restos neontológicos e paleontológicos ao longo de seus condutos, e consideráveis depósitos sedimentares. Em tais documentos, a presença de restos neontológicos é também utilizada como característica para avaliar o potencial fossilífero de cavidades naturais.

\section{Aspectos sedimentológicos e deposicionais}

Na cavidade ES-08 foram identificadas quatro entradas, sendo que três destas estão situadas no nível superior da caverna e dão acesso a um pequeno salão pelo qual se acessa um conduto inferior (porção Oeste), de onde foi retirado o paleopiso (Figura 4). Dessas três entradas, ressalta-se que uma, que é a principal, se acessa a caverna no plano do piso da cavidade (Figura 4D), outra se situa em um nível superior da parede (Figura 4E) e a terceira se trata de uma claraboia (Figura 4F). Já a quarta entrada, localizada na porção Leste do conduto fossilífero, se encontra totalmente preenchida por sedimentos clásticos. (Figura 4G).

Como não há indicativos de direção de fluxo hidráulico e/ ou de sedimentos na caverna, não se pôde verificar por qual entrada (leste ou oeste) o material que forma o paleopiso foi carreado ao conduto. Porém, atualmente a única entrada acessível ao conduto se situa na porção oeste, que é por onde o material neontológico foi carreado e depositado nos sedimentos sobre o piso da caverna. 


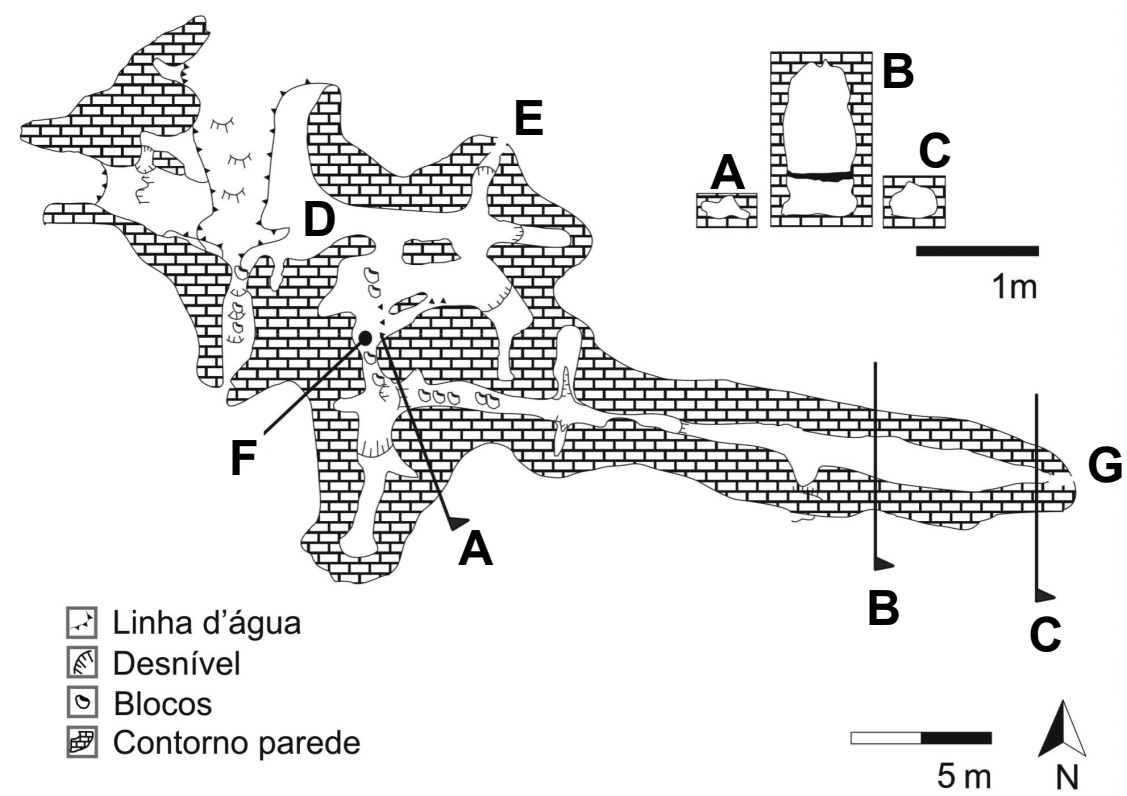

Figura 4. Planta baixa da cavidade ES-08 e cortes do conduto de onde foi retirado o paleopiso (A-C). As entradas da cavidade (D-E), assim como a localização da claraboia (F) e entrada preenchida por sedimentos (G). No corte B pode ser vista a localização do paleopiso. (Modificado de MC Ambiental Ltda).

Figure 4. Plan map of the cave and the cross sections of its conduct, where the hanging layer was removed (A-C). The cave entrances (D-E), the skylight (F), and sediment filled entrance $(\mathbf{G})$. At the section $\mathbf{B}$ the localization of the fossiliferous hanging layer is indicated. (Modified of MC Ambiental Ltda).

O paleopiso que se encontrava suspenso pelas paredes norte e sul do conduto, tem composição siltico-argilosa cimentada por carbonatos e dimensões aproximadas em metros de 1,20x0,60 (em planta) e de 0,94 (em perfil).

A matriz siltico-argilosa do paleopiso se apresentou homogênea, de cor avermelhada, com a presença de grãos milimétricos de óxido de manganês, que também se encontravam em meio ao sedimento da caverna. Sua morfologia tanto em planta, quanto em perfil era irregular e apresentava alvéolos, provavelmente esculpidos por correntes de água, os quais se apresentavam preenchidos por sedimentos condizentes com os que recobrem todo o piso da caverna.

Tais sedimentos também se apresentavam homogêneos, de composição síltico-argilosa, de coloração marrom, com grãos de óxido de manganês e restos de matéria orgânica, incluindo microvertebrados. Além dessas características, o sedimento que encobria o paleopiso também apresentou gretas de contração.

\section{Composição taxonômica}

Foram coletados 191 bioclastos dos quais 40 apresentaram condições de identificação taxonômica, tratando-se de fragmentos de vertebrados de porte pequeno, médio, grande e mega (vide Apêndice 1, Figuras 7-9). Dos 40 ossos identificados, todos pertencentes a mamíferos, foram encontradas uma peça como da família Mylodontidae, e outra pertencente à espécie Eira barbara Linnaeus, 1758. Duas peças foram atribuídas à ordem Lagomorpha; duas a Dasypus novemcinctus Linnaeus, 1758; duas a Speothos sp.; sete a Cuniculus major Lund, 1837 e 25 ossos à Tayassu pecari (Link, 1795) (Figura 5).
As peças esqueletais mais representativas consistem em ossos longos, costelas e falanges, enquanto as menos representativas se tratam de fragmentos de crânio, mandíbula, dentes e osteodermos (Figura 6). Já as demais 151 peças classificadas como indeterminadas consistem em fragmentos ósseos em avançado estágio de fragmentação (Figura 6).

\section{Perfil ontogenético}

O perfil ontogenético traçado a partir das peças identificadas taxonomicamente indicou que das quarenta peças aqui apresentadas nove foram associadas a animais jovens, vinte e uma a animais adultos ( $53 \%$ das peças) e oito não puderam ser determinadas, sendo uma peça de milodontídeo, quatro de Tayassu pecari e duas peças de Cuniculus major e duas de Dasypus novemcinctus (Figura 10).

\section{Representatividade óssea (índices de MNI e NISP)}

Na Tabela 1 são apresentados os valores de MNI e NISP para o material identificado proveniente do paleopiso da cavidade ES-08, onde se vê em linhas gerais que os índices são semelhantes. Apenas uma significativa diferença é vista para os táxons de Tayassu pecari e Cuniculus major.

De Speothos sp. foram coletados dois fêmures direitos e por se tratarem da mesma peça anatômica, contribuiu para que os índices fossem de mesmo valor para este táxon. Também foram recuperados dois osteodermos de Dasypus novemcinctus, que apesar de apresentarem as mesmas feições, como coloração, estágio ontogenético e ausência de alterações, optou-se aqui em não classificá-las como pertencente ao mesmo indivíduo, uma vez que se trata de peças semelhantes, podendo ocupar a mesma posição anatômica. 


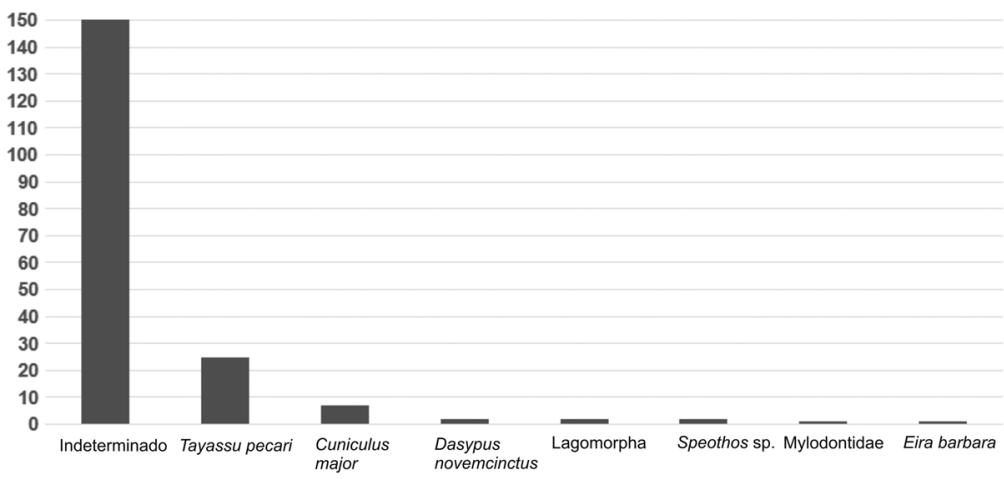

Figura 5. Número dos elementos ósseos de acordo com os táxons coletados no depósito da cavidade ES-08.

Figure 5. Number of skeletal parts according to different taxa in the ES-08 cave deposit.

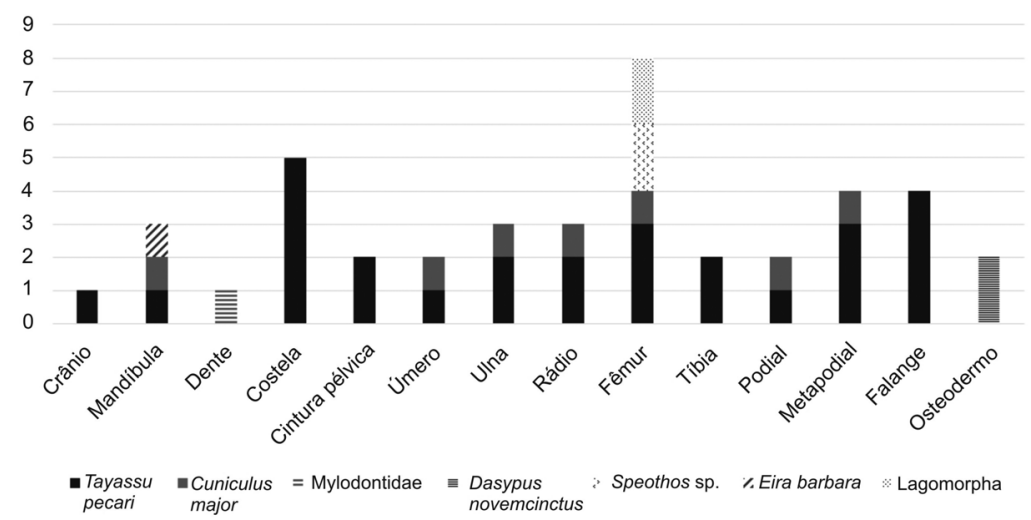

Figura 6. Números de partes esqueletais de acordo com cada táxon recuperado no depósito da cavidade ES-08.

Figure 6. Numbers of skeletal parts according to each taxon recovered in the ES-08 cave deposit.

Tabela 1. Valores dos índices MNI e NISP para os táxons recuperados na cavidade ES-08.

Table 1. MNI and NISP values according to recovered taxa in the ES-08 cave.

\begin{tabular}{lcc}
\hline Táxon & MNI & NISP \\
\hline Tayassu pecari & 3 & 25 \\
Cuniculus major & 1 & 7 \\
Mylodontydae & 1 & 1 \\
Dasypus novemcinctus & 2 & 2 \\
Speothos sp. & 2 & 2 \\
Eira barbara & 1 & 1 \\
Lagomorpha & 1 & 1 \\
\hline
\end{tabular}

Para Mylodontydae e Eira barbara foram identificadas apenas uma peça para cada táxon, o que contribuiu para a igualdade dos índices. Em relação à Lagomorpha as duas peças foram consideradas como partes do mesmo fêmur, pois durante o preparo do material constatou-se que os ossos se encaixaram, evidenciando que a peça esqueletal se fragmentou em momento anterior a cimentação do paleopiso.

\section{Feições bioestratinômicas e fossildiagenéticas}

Em relação ao grau de fragmentação (Figura 11), dez peças foram classificadas na categoria I, como íntegras (17\%), duas na categoria II, como parcialmente íntegras $(33 \%)$ e 28 na categoria III, como fragmentadas $(50 \%)$.

Foram identificadas 30 peças com sinais de abrasão ( $75 \%$ das peças) e 23 apresentaram fissuras (57\% das peças) (Figuras $12,13)$. No que diz respeito ao preenchimento de calcita das cavidades dos ossos (poros e canal medular) verificamos que trinta e um elementos apresentaram algum tipo de precipitação deste mineral (77\% das peças) (Figuras 12,14).

\section{DISCUSSÃO}

\section{Características gerais da área}

Como descrito por diversos pesquisadores que trabalharam na região de Lagoa Santa, a maioria parte dos depósitos fossilíferos contidos na área dos maciços Escrivânia, Limeira e Ingleses mostrou que o material paleontológico, quando encontrado, se apresentava em alto grau de fragmentação e cimentado em matrizes de solo carbonatado, tornando extremamente difícil a retirada in situ dos ossos sem causar danos ao material (e.g. Lund, 1838; Paula Couto, 1958). 
$\mathbf{A}$

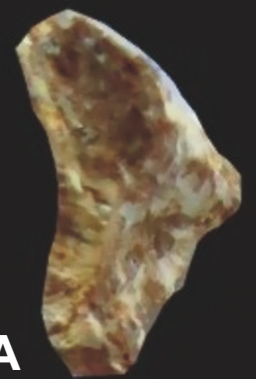

B

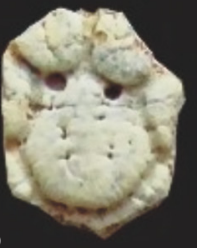

$\mathbf{E}$

D
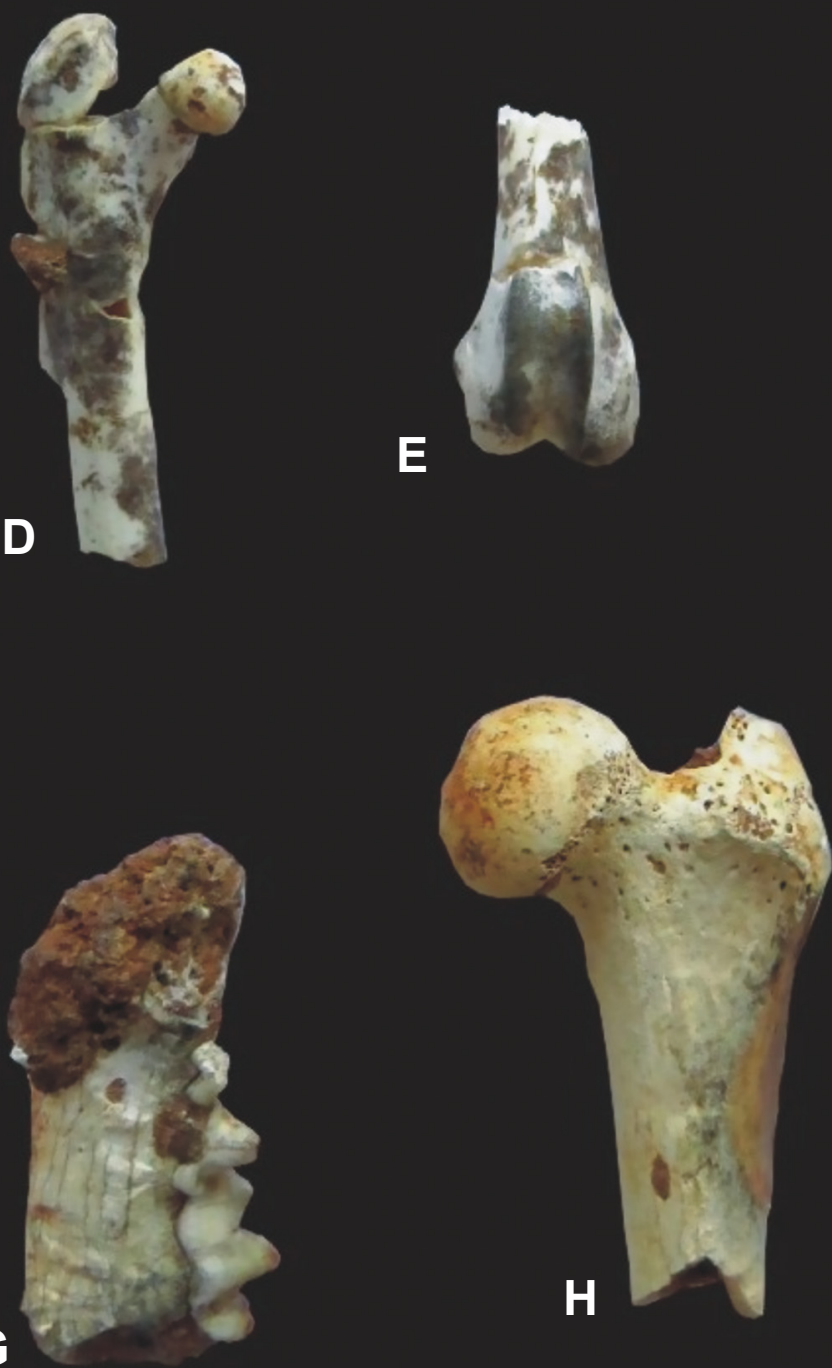

C

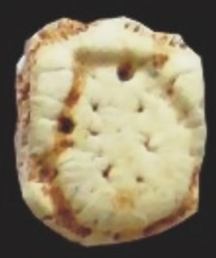

$\mathbf{F}$

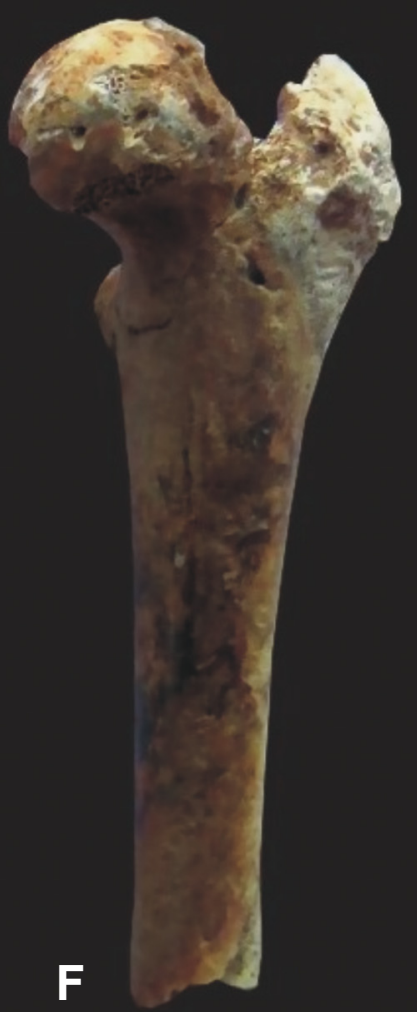

G

Figura 7. Partes esqueletais coletadas e identificadas. A, fragmento de molariforme de Milodontydae (IGC/0586); B, osteodermo de Dasypus novemcinctus (IGC/0587); C, osteodermo de D. novemcinctus (IGC/0588); D, fragmento de fêmur de Lagomorpha (porção proximal) (IGC/0593); E, fragmento de fêmur de Lagomorpha (porção distal) (IGC/0592); F, fragmento proximal de fêmur direito de Speothos sp. (IGC/0589); G, ramo mandibular de Eira barbara (IGC/0591); H, fragmento proximal de fêmur direito de Speothos sp. (IGC/0590). Escala = 20 mm.

Figure 7. Skeletal parts collected and identified. A, fragment of molariform of Milodontydae (IGC/0586); B, osteoderm of Dasypus novemcinctus (IGC/0587); C, osteoderm of $D$. novemcinctus (IGC/0588); D, fragmentary femur of Lagomorpha (proximal portion) (IGC/0593); E, cranial view of fragmentary femur of Lagomorpha (distal portion) (IGC/0592); F, proximal fragment of the right femur of Speothos sp. (IGC/0589) G, mandibular ramus of Eira barbara (IGC/0591); H, proximal fragment of the right femur of Speothos sp. (IGC/0590). Scale bar = 20 mm. 


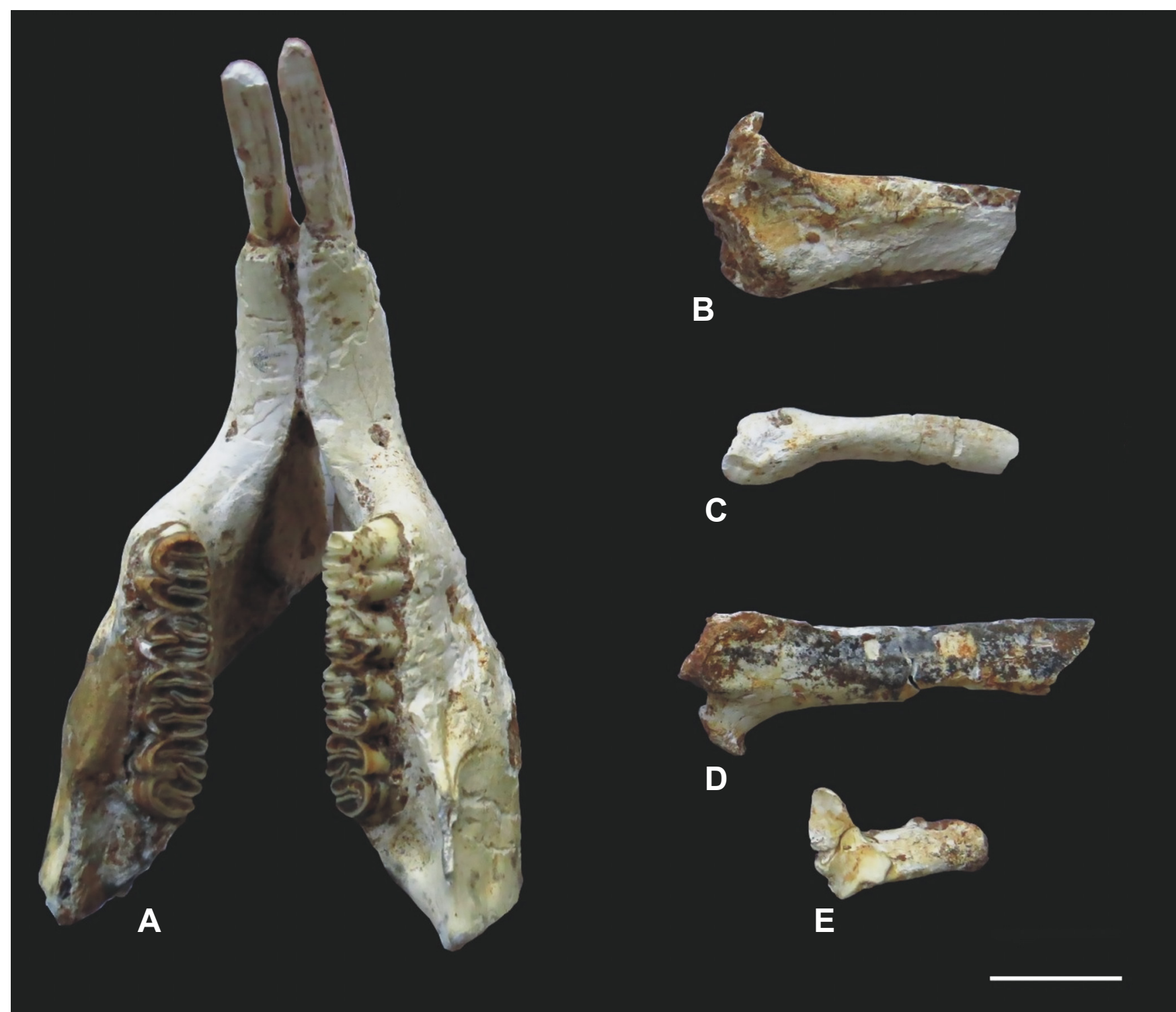

Figura 8. Partes esqueletais de Cuniculus major. A, mandíbula (IGC/0579); B, úmero direito (IGC/0580); C, rádio direito (IGC/0582); D, fêmur esquerdo (IGC/0584); E, calcâneo direito (IGC/0585). Escala $=20 \mathrm{~mm}$.

Figure 8. Skeletal parts of Cuniculus major. A, mandible (IGC/0579); B, right humerus (IGC/0580); C, right radius (IGC/0582); D, left femur (IGC/0584); E, right calcaneous (IGC/0585). Scale bar $=20 \mathrm{~mm}$.

\section{Aspectos sedimentológicos e deposicionais}

Foram identificadas duas entradas possíveis de acesso ao conduto para o carreamento do material formador do paleopiso. Um acesso se encontra completamente preenchido por sedimentos (porção Leste da caverna) (Figura 4G) e, o outro acesso, que tem ligação com o meio externo através de três entradas, ainda recebe aportes sedimentares (Figuras 4D-F). $\mathrm{Na}$ entrada oeste foram verificadas atualmente as entradas de argila e ossos, como restos de quirópteros, roedores e de um esqueleto completo de bovídeo (gênero Bos Linnaeus, 1758). Também por essa entrada, fragmentos ósseos foram depositados sobre as partes erodidas do paleopiso e carregadas por correntes de água. A presença de fragmentos ósseos e blocos rolados depositados juntamente com os sedimentos síltico-argilosos corrobora esta hipótese (Figura 15).
Nas paredes da caverna, em diferentes níveis, também são notadas marcas de enchentes pretéritas, que provavelmente contribuíram com a entrada de sedimentos clásticos e orgânicos na cavidade. Já a comprovação de que houve momentos de inundação após a cimentação do paleopiso se dá pela presença de gretas de contração nos sedimentos depositados sobre a estrutura.

A falta de padrão da distribuição e direção dos bioclastos preservados na matriz sugere três interpretações para a formação do depósito em momento anterior a cimentação por carbonatos: (i) enxurradas carrearam aportes de lama e ossos por fluxos gravitacional e/ou trativo; (ii) eventos posteriores, de novas enxurradas poderiam ter retrabalhado o material. $\mathrm{O}$ retrabalhamento é corroborado pela presença de características fossildiagenéticas muito distintas entre os bioclastos (e.g. cor, 

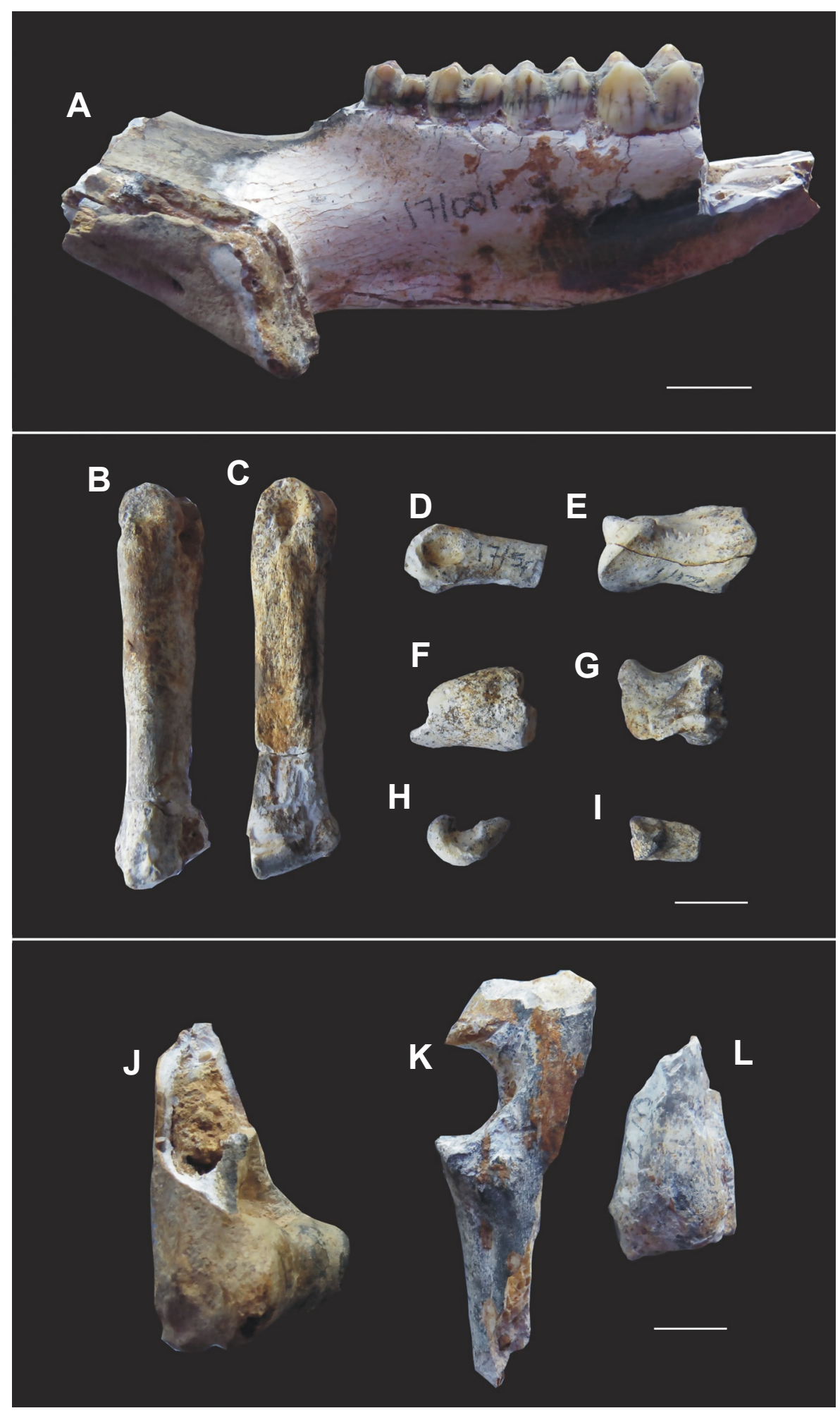

Figura 9. Partes esqueletais de Tayassu pecari, recuperadas no paleopiso da cavidade ES-08. A, ramo mandibular (direito) (IGC/0554); B, metacarpal II (esquerdo) (IGC/0565); C, metatarsal IV (esquerdo) (IGC/0578); D, metacarpal V (IGC/0566); E, falange média do dígito II (IGC/0568); F, falange medial do metatarsal I (IGC/0571); G, unciforme direito (IGC/0564); H, fragmento da porção distal de metapodial (IGC/0567); I, falange média (esquerda) (IGC/0569); J, fragmento distal de úmero (esquerdo) (IGC/0561); K, fragmento proximal de ulna/rádio (esquerdo) (IGC/0562); L, fragmento distal de ulna/rádio (esquerdo) (IGC/0563). Escalas $=20 \mathrm{~mm}$.

Figure 9. Skeletal parts of Tayassu pecari, recovered from hanging layer of ES-08 cave. A, mandibular ramus (rigth) (IGC/0554); B, metacarpal II (left) (IGC/0565); C, metatarsal IV (left) (IGC/0578); D, metacarpal V (IGC/0566); E, middle phalanx of digit II (IGC/0568); F, middle phalanx of metatarsal I (IGC/0571); G, right unciform (IGC/0564); H, distal portion of metapodial (IGC/0567); I, middle phalanx (left) (IGC/0569); J, distal fragment of humerus (left) (IGC/0561); K, proximal fragment of ulna/radius (left) (IGC/0562); L, distal fragment of ulna/radius (left) (IGC/0563). Scale bars $=20 \mathrm{~mm}$. 


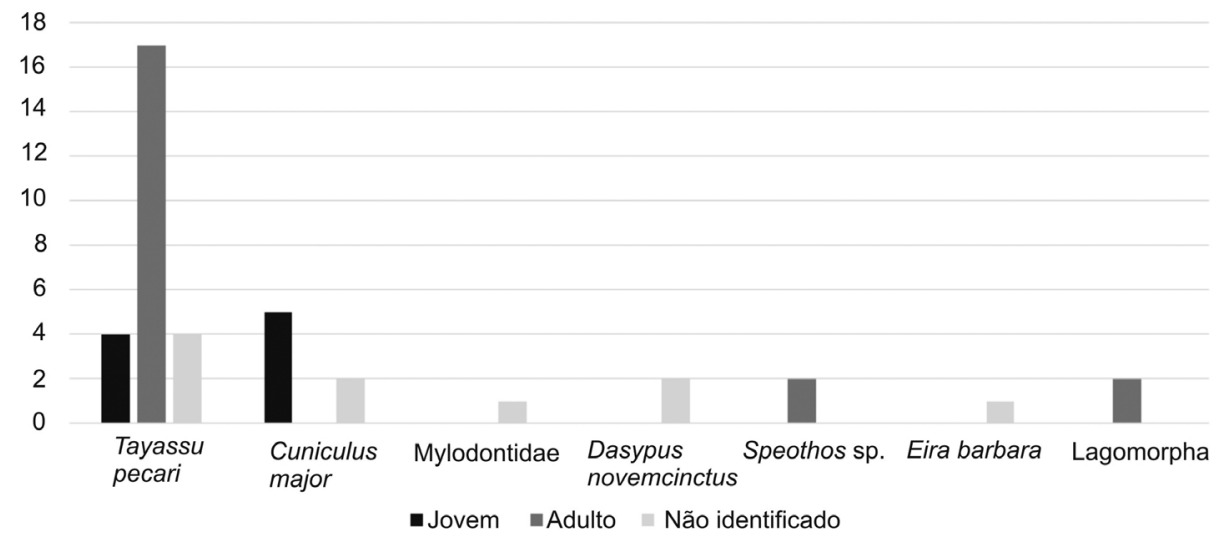

Figura 10. Número de peças esqueletais de acordo com o estágio ontogenético recuperadas na cavidade ES-08.

Figure 10. Number of skeletal parts in according to ontogenetic stages recovered in ES-08 cave.

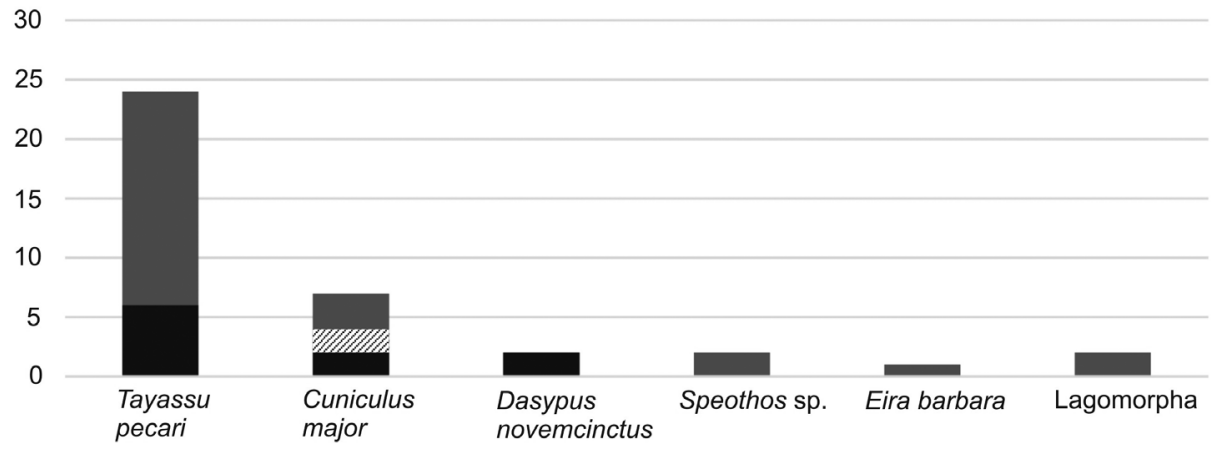

-íntegro (>90\%) «Parcialmente íntegro (89-50\%) —Fragmentado $<50 \%)$

Figura 11. Percentual de fragmentação das partes esqueletais coletadas de acordo com os táxons da cavidade ES-08.

Figure 11. Fragmentation percentage of skeletal parts in the in ES-08 cavity deposit.

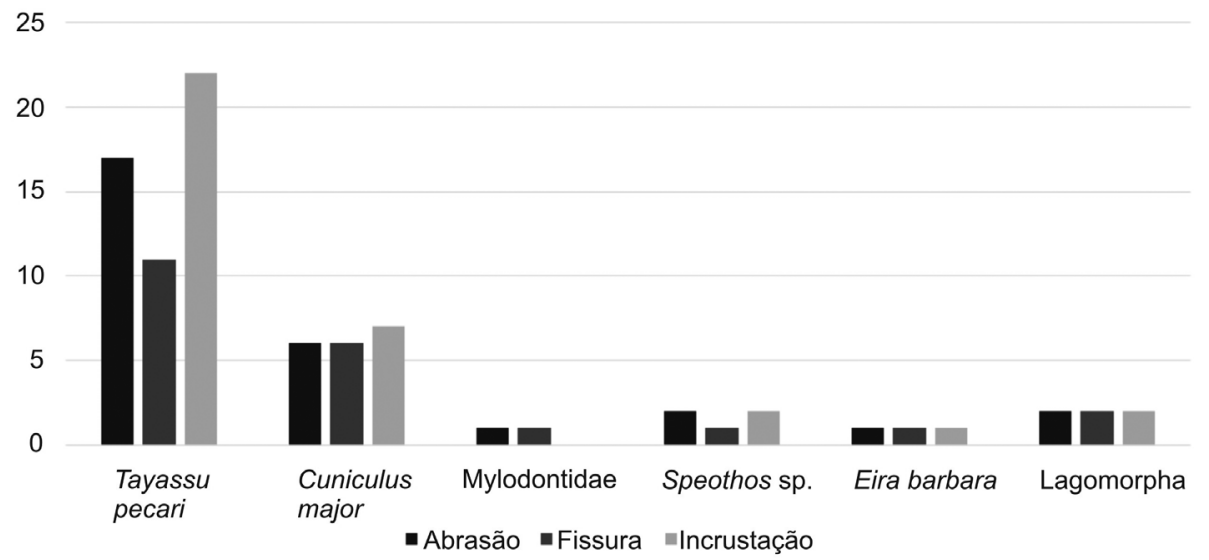

Figura 12. Modificações tafonômicas das partes esqueletais identificadas do depósito da cavidade ES-08.

Figure 12. Taphonomic modifications of identified skeletal parts in the in ES-08 cave deposit. 

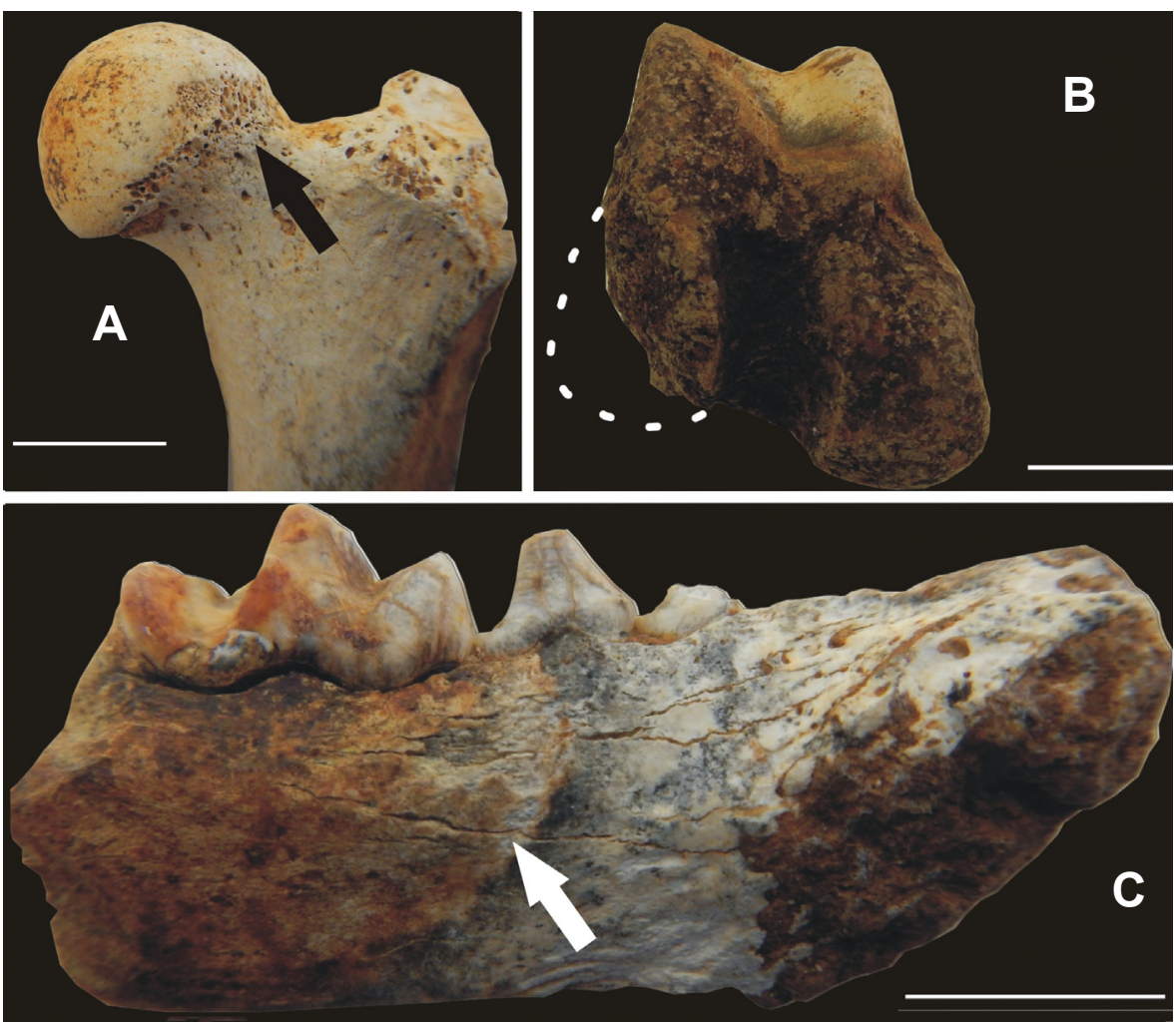

Figura 13. A, abrasão em fêmur de Speothos sp.; B, fêmur fragmentado de Tayassu pecari; C, marcas de dissecação em mandíbula de Eira barbara. Escalas $=20 \mathrm{~mm}$.

Figure 13. A, abrasion in Speothos sp. femur (IGC/0590); B, fragmented femur of Tayassu pecari; C, desiccation marks in Eira barbara mandible. Scale bars $=20 \mathrm{~mm}$.
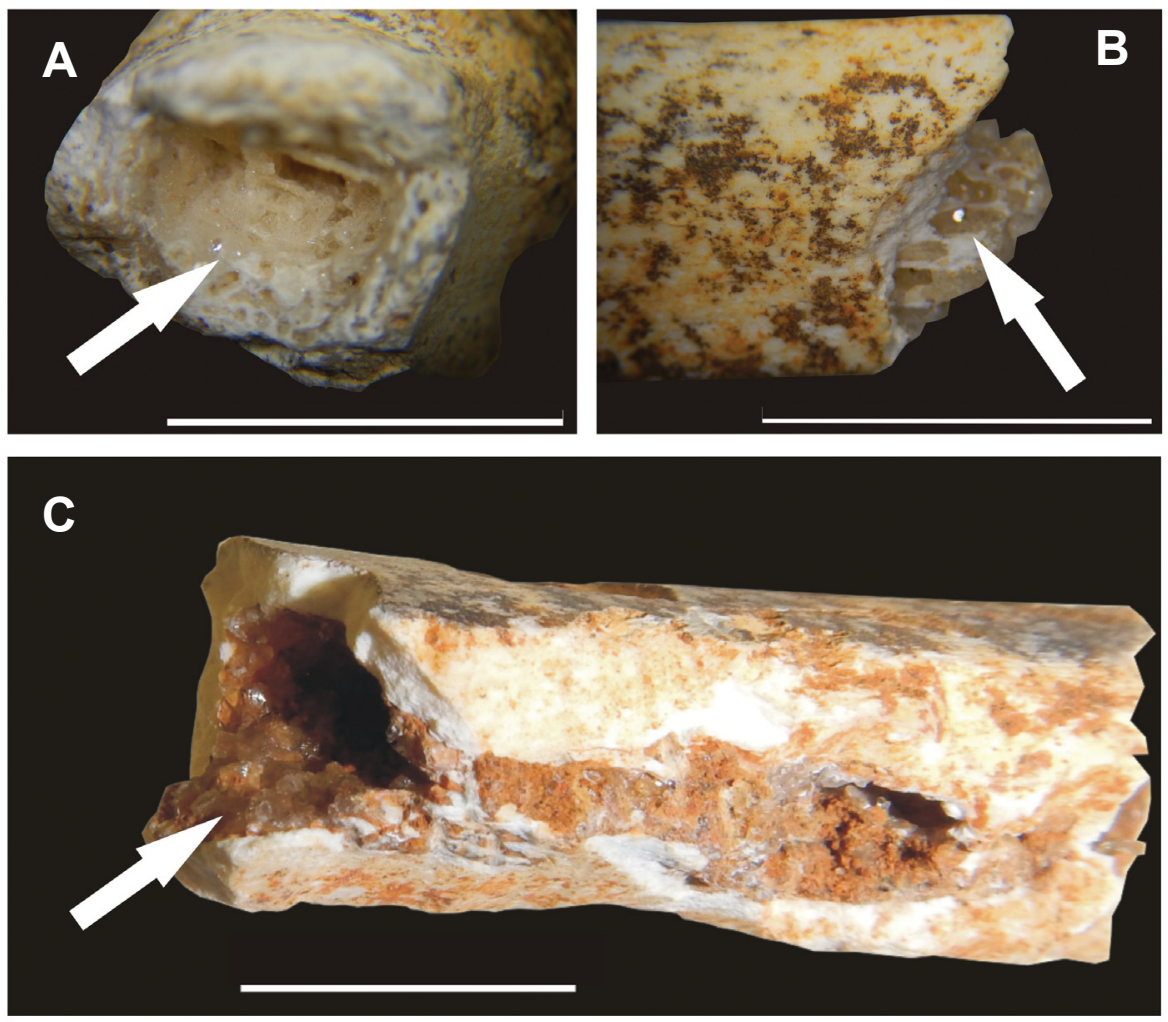

Figura 14. Poros (A-B) e canal medular (C) preenchidos por calcita. Escalas $=20 \mathrm{~mm}$.

Figure 14. Pores (A-B) and medullary cavity (C) filled by calcite. Scale bars $=20 \mathrm{~mm}$. 


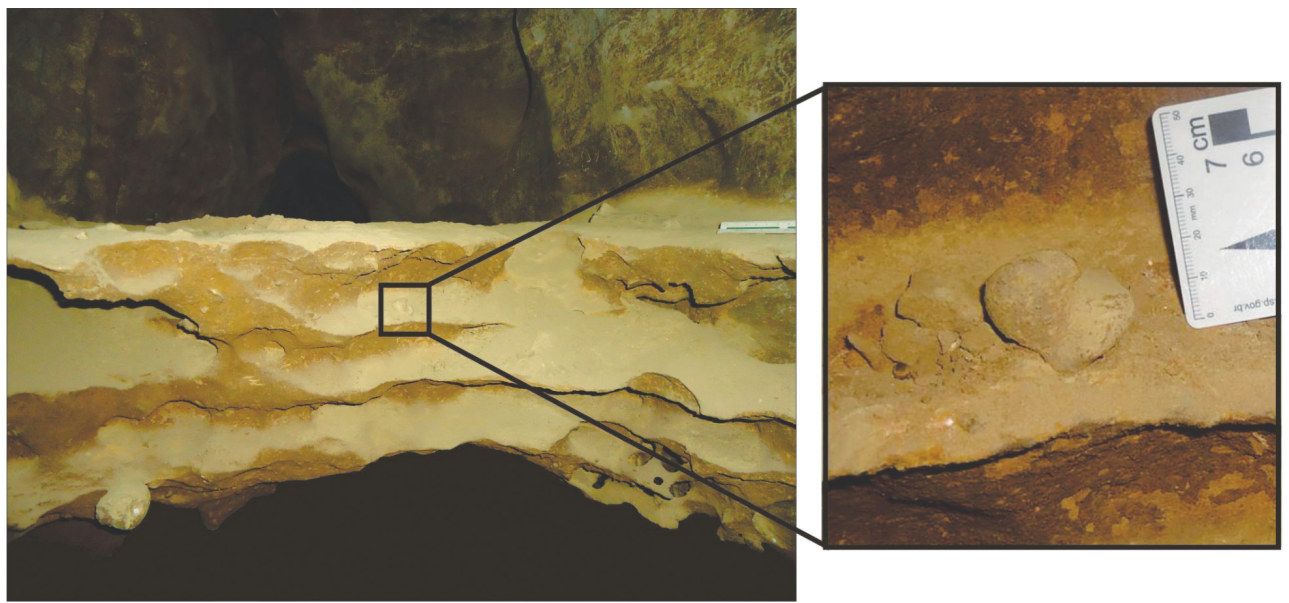

Figura 15. Vista em corte oeste do solo carbonatado, com detalhe da deposição de resto neontológico.

Figure 15. Profile west cut of the carbonate matrix, with a recent bone deposited (see detail).

textura, diferentes graus de preenchimento por calcita) e fazem com que a segunda opção seja mais plausível para a formação do depósito; (iii) ou ainda para a formação da estrutura poderia ser uma combinação desses dois eventos citados.

Características como a forma de deposição dos ossos e sedimentos e as semelhanças fossildiagenéticas entre os bioclastos foram utilizados para interpretações da formação de depósitos fossilíferos em cavidades, como por exemplo, as inseridas no maciço Cerca Grande (Paula Couto, 1958), na Lapa Mortuária (Souza Cunha, 1960) e Gruta na Bauzinho dos Ossos (Almeida, 2000). Tais depósitos também eram compostos por material paleontológico com alto grau de desarticulação, fragmentação e se encontravam espaçados entre si em meio ao depósito.

Outro fator tafonômico muito importante, em se tratando de restos de paleovertebrados preservados em cavernas, são os mecanismos de entrada de animais, ou de seus restos, nas cavidades. Segundo Lund $(1836,1837)$ e Simms (1994), os principais mecanismos de entrada de animais e de seus restos em cavidades são: (i) a entrada nas cavidades dos animais ainda vivos, a procura de abrigo ou (ii) para lamber sal e consequente morte pela incapacidade de encontrar a saída; (iii) queda dos animais em fendas e abismos; (iv) restos carregados por predadores; (v) transporte das carcaças e restos esqueletais pelas enxurradas.

Diferente do observado no depósito da Gruta Cuvieri (MG), onde foram resgatados esqueletos articulados (Hubbe, 2008), características apresentadas no depósito da caverna ES-08 como as ausências de esqueletos parcialmente e/ou totalmente articulados, e de seleção hidráulica das peças, apontam para a formação do depósito por transporte por enxurrada. Fato também observado em outros depósitos de cavernas da região, como relatados por Lund (1836), Paula Couto (1958), Souza Cunha (1960) e Almeida (2000).

Tal característica é condizente com depósitos fossilíferos preservados em cavernas, que em muitos casos, tais ambientes estão expostos a diversos eventos de injeção de sedimentos e/ou água, nos quais retrabalham seus sedimentos fazendo com que as peças esqueletais, principalmente as mais gráceis, sofram fragmentação (e.g. Lund, 1836; 1837; Paula Couto, 1958; Almeida, 2000).

\section{Coleta do paleopiso}

Como os ossos se encontravam cimentados em uma matriz carbonatada compacta, foi inviável a retirada dos fósseis ainda no interior da cavidade. Assim, a opção escolhida foi a de retirar o paleopiso e transportá-lo para o laboratório, onde poderia ser utilizado material apropriado para minimizar os possíveis danos causados aos fósseis durante a retirada da matriz, fato relativamente comum relacionado a situações onde se tenta preparar os fósseis ainda em campo.

Com a adaptação de métodos já descritos, foi possível fragmentar o paleopiso de maneira ordenada, para que não se perdessem as informações de localização dos fósseis ali preservados. Através deste método foi possível a preservação da posição de $90 \%$ dos bioclastos.

Este tipo de coleta, baseado no transporte da matriz sedimentar em blocos, onde são indicadas as posições estratigráficas dos blocos, é muito comum nos em depósitos expostos em afloramentos mais antigos, como os mesozoicos e paleozoicos, e não relatado para coletas em cavernas (e.g. Eberth, et al., 2007; Bertoni-Machado, et al., 2008). Almeida (2000) já salientava a importância de novos estudos envolvendo técnicas de coleta controlada para este tipo de substrato em cavernas.

\section{Composição taxonômica e perfil ontogenético}

Apesar do pouco volume de ossos retirado da caverna, quando comparado com outros estudos tafonômicos efetuados na região (Almeida, 2000; Hubbe, 2008; Mayer, 2011) o depósito da cavidade ES-08 apresentou uma elevada diversidade, apresentando sete grupos taxonômicos. Todos os táxons encontrados na cavidade ES-08 possuem registros para o carste de Lagoa Santa. Atribuímos um maior destaque aos restos de Lagomorpha por se tratar do primeiro registro fóssil desta ordem para a região de Lagoa Santa desde os estudos de Peter Lund no século XIX. 
Em relação ao perfil ontogenético, como não houve predomínio de faixas etárias relacionadas a um determinado táxon no depósito, pôde-se constatar que não houve seleção de morte dos espécimes. Aspecto semelhante aos trabalhos desenvolvidos em depósitos de cavernas carbonáticas. Embora deve-se salientar que o perfil ontogenético não é comum de ser traçado em trabalhos envolvendo fósseis de vertebrados em depósitos cavernícolas, acarretando assim em uma carência de dados para se comparar com as informações obtidos na cavidade ES-08 (e.g. Paula Couto, 1958; Almeida, 2000; Castro \& Langer, 2008; Hubbe \& Auler, 2012; Mayer, 2013).

Tais características quando analisadas em conjunto com outros aspectos do depósito, como a variedade faunística composta por animais de diferentes pesos e a disposição caótica dos bioclastos na matriz, indicam que houve uma baixa, ou nenhuma seleção das peças durante o processo de sua entrada e incorporação ao sedimento na caverna, fato que corrobora com que houve, para formação do depósito, transporte por fluxo de lama e /ou retrabalhamentos posteriores (Haynes, 1980; Wang \& Martin, 1993; Kos, 2003) (Figura 16). Característica também observada em depósitos das grutas da região de estudo (Lund, 1936; Paula Couto, 1958; Almeida, 2000; Hubbe, 2008; Mayer, 2011).

\section{Representatividade óssea (índices de MNI e NISP)}

A quantidade de peças esqueletais resgatadas na cavidade ES-08, pode estar diretamente relacionada ao volume total de área escavada. Na cavidade ES-08, o volume escavado foi de aproximadamente $0,68 \mathrm{~m}^{3}$, um pequeno volume quando comparado aos trabalhos realizados por Almeida (2000) na Gruta Bauzinho dos ossos, onde foram escavados aproximadamente de $7 \mathrm{~m}^{3}$ de sedimento e coletados 118 bioclastos, e na Gruta Cuvieri, onde Hubbe (2008) e Mayer (2011) escavaram em três áreas dessa caverna, cerca de $13 \mathrm{~m}^{3}$ e coletaram no total 7545 bioclastos.

Desta forma, nessas cavidades, onde foi retirado um volume de sedimento muito superior ao retirado da cavidade ES-08, resultou também em uma maior quantidade de bioclastos recuperados.

Outros trabalhos desenvolvidos no carste de Lagoa Santa, como os conduzidos por Lund (1837), Walter (1943), Paula Couto (1968), também proporcionaram um elevado número de bioclastos, porém como esses pesquisadores não mencionam o volume de sedimento retirado das cavernas, assim não há como verificar e comparar esta questão com o presente trabalho.

Fatores como o alto grau de dispersão dos bioclastos na matriz carbonatada e as próprias características do depósito, que sugerem a sua formação por fluxo de lama, o qual carreou as peças esqueletais de maneira desordenada, poderiam apontar para o uso do índice NISP, o qual é aplicado em circunstâncias onde os bioclastos possam ter sofrido um acentuado transporte e retrabalhamento antes de seu sepultamento.

Porém, por se tratar de um número reduzido de táxons identificados, pelos ossos apresentarem características semelhantes (e.g. estágio ontogenético) e a ausência de repetição de peças esqueletais homólogas para a maioria dos táxons, o índice MNI para o depósito da cavidade ES-08 seria o mais adequado.

Houve repetição de elementos esqueletais para três táxons, que foram dois fêmures esquerdos de Tayassu pecari, dois fêmures direitos de Speothos sp. e dois osteodermos de Dasypus novemcinctus, que devido às semelhanças apresentadas por estas, provavelmente poderiam pertencer ao mesmo indivíduo.
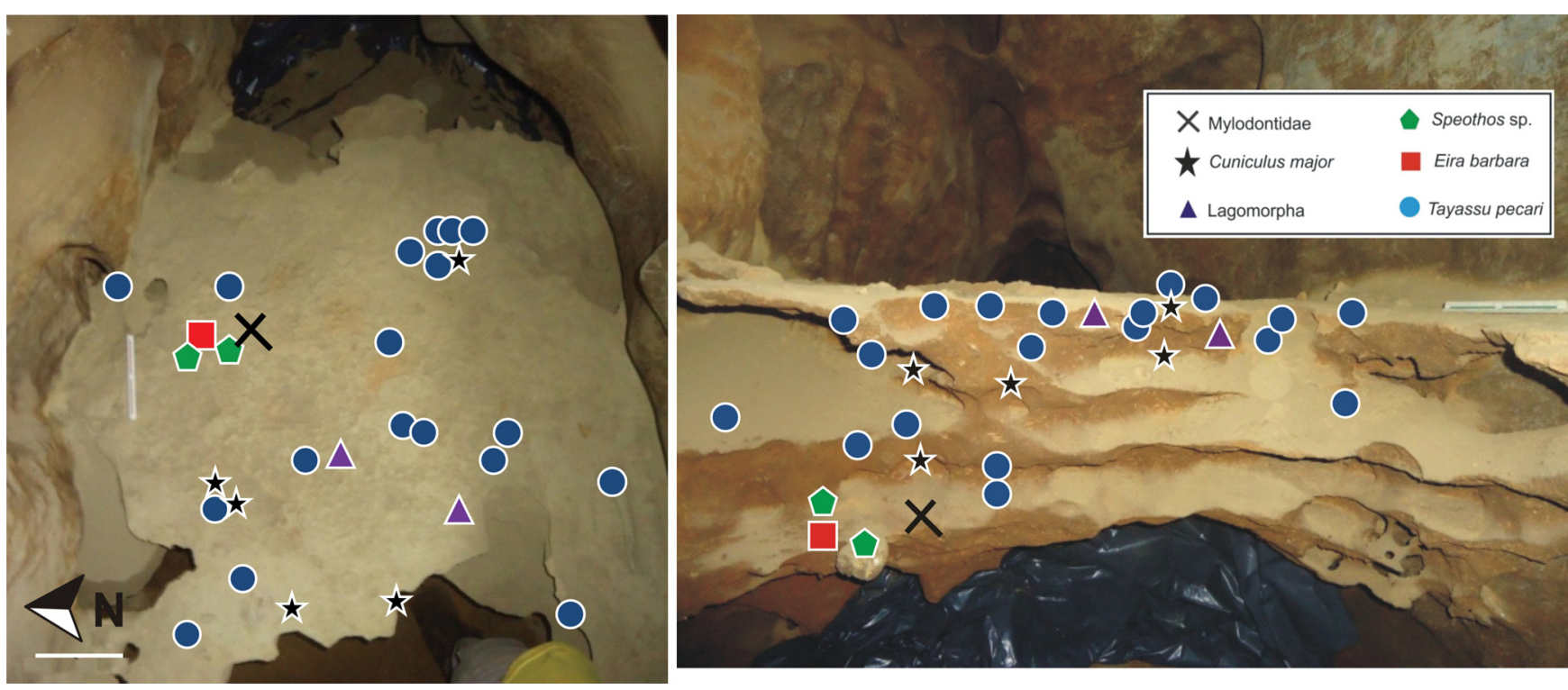

Figura 16. Vista em planta baixa (esquerda) e em corte (direita) do paleopiso com a distribuição dos fósseis identificados. A posição das peças de Dasypus novemcinctus é incerta. Escala $=150 \mathrm{~mm}$.

Figure 16. Plan view (left) and cut view (right) of the hanging layer with the fossils distribution. The position of Dasypus novemcinctus bones is uncertain. Scale bar $=150 \mathrm{~mm}$. 
Já para Lagomorpha, mesmo havendo dois bioclastos, considerou-se na contagem como sendo apenas um, uma vez que durante o preparo do material, constatou-se que os fragmentos pertenciam ao mesmo fêmur.

Os demais táxons representados no depósito por mais de um osso, não apresentaram peças homólogas repetidas, fato que corrobora com a aplicação do índice MNI para a quantificação de indivíduos no depósito.

\section{Feições bioestratinômicas e fossildiagenéticas}

Em geral, o grau de fragmentação está relacionado as características dos ossos, como por exemplo, a robustez, quantidade de arestas, ao tipo de transporte sofrido pelos bioclastos ou até mesmo a posição espacial dos bioclastos no depósito (e.g. Lund, 1837; Shipman, 1981).

Desta forma, peças pequenas, porém compactas, como os osteodermos de Dasypus novemcinctus, não sofreram fragmentação, assim como podiais de Tayassu pecari no depósito da cavidade ES-08. Já as peças mais gráceis, como crânio, costelas e ossos da cintura pélvica, apresentaram um elevado grau de fragmentação, que pode ser atribuído ao transporte e/ou retrabalhamento do depósito.

Padrões nas alterações dos bioclastos associados a um tipo específico de agente já foram reportados para bioclastos coletados em cavernas brasileiras, porém, na cavidade ES08 tais padrões não foram observados, como por exemplo, a ação de agentes biológicos (e.g. Lund, 1836; Lino, et al., 1979; Barros et al., 1984).

Em relação as alterações sofridas pelos bioclastos relacionadas a posição espacial no depósito, foi observado que as porções dos ossos que se encontravam expostos sofreram alterações como abrasão e alteração de sua coloração. Os efeitos abrasivos são condizentes com a percolação da água sobre os bioclastos e a alteração da coloração dos ossos depositados em cavernas está relacionada ao contato com minerais presentes na caverna, como óxido de ferro, que neste caso alterava a coloração do osso para tons escuros, como foi observado em porções da mandíbula de Tayassu pecari, ilustrada na Figura 9A (Lund, 1837; 1838).

As feições observadas nas peças condizem com as feições apresentadas por material fóssil coletado em outras cavernas tanto da região de Lagoa Santa, como de outras localidades do Brasil, como cavernas situadas no Vale do Ribeira (e.g. Lund, 1836; Barros et al., 1984; Perônico \& Araújo, 2002; Castro \& Langer, 2008). Trata-se de peças com alto grau de fragmentação, abrasão, com o depósito apresentando uma significativa mistura de diferentes peças esqueletais, pertencentes a diferentes táxons e de estágios ontogenéticos distintos. Já características como ação de agentes biológicos e de predadores, que foi observada em outros depósitos cavernícolas, não ocorrem no depósito da caverna ES-08 (e.g. Lund, 1836; Paula Couto, 1958; Lino, et al., 1979, Barros et al., 1984).

Todo o material coletado, e identificado até o momento, na cavidade ES-08 se trata de mamíferos, fato também observado em trabalhos realizados em diferentes cavernas brasileiras, onde se coletou uma maior quantidade de restos de mamíferos quando se comparado com as demais Ordens (e.g. Lund, 1837; Walter, 1943; Paula Couto, 1958; Perônico \& Araújo, 2002; Castro \& Langer, 2008; Hubbe, 2008).

Perônico \& Araújo (2002) afirmam que métodos de coleta controlados podem ser favoráveis a recuperação de peças esqueletais diminutas e assim, aumentar o número de táxons recuperados, principalmente de microvertebrados. No entanto, no depósito da caverna ES-08, mesmo havendo controle no momento da coleta, apenas uma ínfima parcela destas pequenas peças esqueletais preservadas puderam ser identificadas, o que mostra que não é apenas o fato da coleta ser controlada que permite o resgate de peças delicadas em depósitos cavernícolas. Os processos atuantes durante a formação do depósito representam uma significativa parcela nos efeitos destrutivos dos ossos, fato este corroborado pelo elevado número de bioclastos fragmentados coletados no paleopiso da cavidade ES-08, sendo atribuídos ao transporte e/ou retrabalhamento.

Já o processo de permineralização dos carbonatos nos ossos não alterou suas características morfológicas, como é observado em fósseis que sofrem distorções causadas por precipitações de minerais em seu interior (e.g. Holz \& Schultz, 1998). Os ossos coletados no paleopiso apresentaram apenas precipitações parciais em seus poros e/ou canais.

Modificações do tipo fissuras podem surgir no osso devido ao intemperismo sofrido pelas peças em momento anterior ao soterramento (e.g. Behresmeyer, 1978; Andrews, 1990; Lyman, 1994). Neste sentido, pôde-se inferir a formação do depósito não foi sincrônica, uma vez que há ossos que permaneceram um maior tempo expostos às intempéries, apresentando fissuras, enquanto outros foram soterrados em um curto espaço de tempo, não apresentando tais modificações.

Para haver a precipitação de minerais nos poros e cavidades dos ossos é necessário que estes permaneçam por um determinado tempo em um ambiente aquoso saturado desses minerais. Assim, com o posterior escoamento (ou evaporação) da água, tais minerais se precipitam ou sobre o material, ou em seu interior. As próprias características do depósito já fornecem informações a respeito dessa precipitação de minerais nos poros do sedimento, que por sua vez o cimentou, formando assim o solo carbonatado. Assim, era de se esperar que o material ali preservado também assumisse tais características, sendo tomado por minerais em seus poros, fato que foi confirmado através da análise das peças fragmentadas (e.g. Lund, 1836; Hill et al., 1976; Teixeira, 1980; Cartelle, 1994; Guidon et al., 2009).

Em linhas gerais, no que diz respeito ao estado de preservação dos fósseis depositados em cavernas se assemelham com o material coletado em tanques naturais, que também, por características geomorfológicas da região onde estão inseridos, tendem a receber fluxos de enxurradas e/ou de lama que por sua vez, além de depositar novos bioclastos, retrabalham o sedimento já depositado, contribuindo assim para a fragmentação, ou até mesmo destruição, do material ali anteriormente depositado (e.g. Ximenes, 2009; AraújoJúnior et al., 2013). 


\section{CONCLUSÕES}

O estudo tafonômico dos fósseis da cavidade ES-08 mostrou que a formação do depósito em momento anterior à cimentação por carbonatos se deu através de enxurradas que carrearam aportes de lama e ossos por fluxos gravitacional e/ou trativo e que eventos posteriores, de novas enxurradas poderiam ter retrabalhado o material. As evidências que reforçam este modelo são: (i) a falta de padrão da distribuição e direção dos bioclastos preservados no paleopiso, a partir da observação da localização em planta e seção dos restos fósseis; (ii) o alto grau de fragmentação, abrasão, a significativa mistura de diferentes peças esqueletais, pertencentes a diferentes táxons e de estágios ontogenéticos distintos; (iii) o elevado grau de fragmentação, a ausência de esqueletos articulados e a presença de dois fragmentos localizados em posições distintas na matriz.

Os resultados mostraram o potencial da análise tafonômica com coleta controlada de paleopiso carbonatado e estudos das feições macroscópicas dos fósseis no contexto das cavidades inseridas em relevos cársticos brasileiros.

\section{AGRADECIMENTOS}

Este trabalho foi realizado no âmbito do projeto "Levantamento Paleontológico das Cavidades Naturais" com recursos da Mineração Sandra SA. O primeiro autor agradece a Coordenação de Aperfeiçoamento de Pessoal de Nível Superior (CAPES) pela concessão da bolsa de mestrado. Os autores agradecem aos pesquisadores das coleções de Mastozoologia e Paleontologia do Museu de Ciências Naturais PUC-Minas, especialmente a C. Cartelle e L. Vilaboim, pelo suporte dado durante a identificação dos fósseis. Também agradecem aos dois revisores anônimos pelas sugestões e correções que contribuíram para a melhoria do manuscrito.

\section{REFERÊNCIAS}

Alkmim, F.F. \& Martins-Neto, M.A. 2001. A Bacia intracratônica do São Francisco: arcabouço estrutural e cenários evolutivos. In: C.P. Pinto \& M.A. Martins-Neto (eds.) Bacia do São Francisco: Geologia e Recursos Naturais, SBG/Núcleo MG, p. 9-30.

Almeida, C.P. 2000. Abordagem tafonômica do jazigo fossilifero, sd-1, da gruta Bauzinho de Ossos, região cárstica de Lagoa Santa, Minas Gerais. Programa de Pós-graduação em Geologia, Universidade Federal do Rio de Janeiro, Dissertação de Mestrado, $80 \mathrm{p}$.

Ameghino, F. 1907. Notas sobre una pequeña colección de huesos de mamíferos procedentes de las grutas calcárias de Iporanga, em el estado de São Paulo, Brazil. Revista do Museu Paulista, 3:59-124.

Andrews, P. 1990. Owls, caves and fossils. Chicago, The University of Chicago Press, $231 \mathrm{p}$.

Araújo-Júnior, H.I.; Bissaro Júnior, M.C.; Santos, T.T.; Alves, R.S. \& Bergqvist, L.P. 2012. Tafonomia da megafauna pleistocênica brasileira: fluvial transport index (fti) em análises de representatividade óssea. Revista Brasileira de Paleontologia, 15:95-104. doi:10.4072/rbp.2012.1.08

Araújo-Júnior, H.I.; Porpino, K.O.; Ximenes, C.L. \& Bergqvist L.P. 2013. Unveiling the taphonomy of elusive natural tank deposits: a study case in the Pleistocene of northeastern Brazil. Palaeogeography, Palaeoclimatology, Palaeoecology, 378:5274. doi:10.1016/j.palaeo.2013.04.001

Auler, A.S. 1994. Hydrogeological and hydrochemical characterization of the Matozinhos - Pedro Leopoldo Karst, Brazil. Department of Geography and Geology, Western Kentucky University, M.Sc. Dissertation, 110 p.

Auler, A.S.; Piló, L.B.; Smart, P.L.; Wang, X.; Hoffmann, D.; Richards, D.A.; Edwards, R.L.; Neves, W.A. \& Cheng, H. 2006. U-series dating and taphonomy of Quaternary vertebrates from Brazilian caves. Palaeogeography, Palaeoclimatology, Palaeoecology, 204:508-522. doi:10.1016/j.palaeo.2006.03.002

Badgley, C. 1986. Counting individuals in mammalian fossil assemblages from fluvial environments. Palaios, 1:328-338. doi: $10.2307 / 3514695$

Barros, C.N.B.; De Blasiis, P.A.D.; Robrahn, E.M.; Dias Neto, C.M.; Karmann, I. \& Lino, C.F. 1984. Abismo Ponta de Flecha: um projeto arqueológico, paleontológico e geológico no médio curso do Ribeira de Igapé, SP. Espeleotema, 14:22-35.

Behrensmeyer, A.K. 1991. Terrestrial vertebrate accumulations. In: P. Allison \& D.E. Briggs, (eds.) Taphonomy: releasing the data locked in the fossil record, Plenum, p. 291-335.

Behrensmeyer, A.K. 1978. Taphonomic and ecologic information from bone weathering. Paleobiology, 4:150-162.

Beisaw, A.M. 2013. Identifying and interpreting animal bones: a manual. $1^{\text {st }}$ ed. College Station, Texas A\&M University Press, $192 \mathrm{p}$.

Bergqvist, L.P. \& Almeida, E.B. 2003. Inventário de ocorrências de mamíferos fósseis no Brasil. In: CONGRESSO BRASILEIRO DE PALEONTOLOGIA, 18, 2003. Boletim de Resumos, Brasília, UNB, p. 64-65.

Bergqvist, L.P. \& Almeida, E.B. 2004. Biodiversidade de mamíferos fósseis brasileiros. Revista da Universidade de Guarulhos, 9:54-68.

Bertoni-Machado, C.; Kislowski, F.F.; Soares, M.B. \& DentzienDias, P.C. 2008. Uma peculiar tafocenose controlada por ação biogênica no Triássico Médio do Rio Grande do Sul, Brasil. Pesquisas em Geociências, 35:57-69.

Brasil, 2009. Instituto do Patrimônio Histórico e Artístico. Portaria n. 28, de 31 janeiro de 2003. Diário Oficial da União, Brasília, DF, 03 fev. 2003. Brasil. Ministério do Meio Ambiente. Instrução normativa n.2, de 20 de agosto de 2009. Diário Oficial da União, Brasília, DF, 21 ago. 2009. Seção 1. p. 68.

Brito, I.M. 1979. Bacias sedimentares e formações pós-paleozoicas do Brasil. Rio de Janeiro, Interciência, 179 p.

Buchmann, F.S.C. 2002. Bioclastos de organismos terrestres e marinhos na praia e plataforma interna do Rio Grande do Sul: natureza, distribuição, origem e significado geológico. Programa de Pós-Graduação em Geociências, Universidade Federal do Rio Grande do Sul, Tese de Doutorado, 108 p.

Cartelle, C. 1992. Edentata e megamamiferos herbivoros extintos da Toca dos Ossos (Ourolândia, BA, Brasil). Programa de PósGraduação em Morfologia, Universidade Federal de Minas Gerais, Belo Horizonte, Tese de Doutorado, 301 p.

Cartelle, C. 1994. Tempo passado: mamíferos do Pleistoceno em Minas Gerais. Belo Horizonte, Palco, 132 p.

Cartelle C. 2012. Das grutas à luz, mamíferos pleistocênicos de Minas Gerais. Belo Horizonte, Bicho do Mato, 236 p.

Cartelle, C. \& Hartwig, W.A. 1996. A new extinct primate among the Pleistocene megafauna of Bahia, Brazil. Proceedings of the National Academy of Sciences of the United States of America, 93:6405-6409. 
Castro, M.C. \& Langer, M.C. 2008.New postcranial remains of Smilodon populator Lund, 1842 from southeastern Brazil. Revista Brasileira de Paleontologia, 11:199-206. doi: 10.4072/ rbp.2008.3.06

Dantas, M.A.T. 2009. Primeiro registro de fósseis de mamíferos pleistocênicos em caverna de Sergipe, Brasil. Revista Brasileira de Paleontologia, 12:161-164. doi:10.4072/rbp.2009.2.06

Dantas, M.A.T. \& Tasso, M.A.L. 2007. Megafauna do Pleistoceno final de Vitória da Conquista, Bahia: taxonomia e aspectos tafonômicos. Cientia Plena, 3:30-36.

Donato, C.R.; Dantas, M.A.T. \& Barreto, E.A.S. 2008. Ocorrência de morcegos fósseis (Myotis sp.) na Caverna do Bom Pastor, Paripiranga, Bahia, Brasil. In: SIMPÓSIO BRASILEIRO DE PALEONTOLOGIA DE VERTEBRADOS, 4, 2008. Boletim de Resumos, Ribeirão Preto, USP, p. 85-86.

Eberth, D.A.; Rogers, R. \& Fiorillo, A.R. 2007.A practical approach to the study of bonebeds. In: R. Rogers; D.A. Eberth \& A.R. Fiorillo (eds.) Bonebeds: genesis, analysis, and paleobiological significance, University of Chicago Press, p. 265-331.

Ferreira, D.; Silva, A.K.B.; Matos, C. H.C.; Hadler, P. \& Hsiou, A.S. 2012. Assembleia holocênica de vertebrados de pequeno porte do Sítio Alcobaça, estado de Pernambuco, Brasil. Revista Brasileira de Paleontologia, 15:359-370. doi:10.4072/rbp.2012.3.11

Gilinsky, N.L. \& Bennington, J.B. 1994. Estimating of whole individuals from collections of body parts: a taphonomic limitation of the paleontological record. Paleobiology, 20: 245-258.

Guidon, N.; Guérin, C.; Faure, M.; Felice, G.D.; Buco, C.; Ignácio, E. 2009. Toca das Moendas, Piauí-Brasil: primeiros resultados das escavações arqueológicas. FUMDHAMentos, 8:70-85.

Haynes, G. 1980. Evidence of carnivore gnawing on Pleistocene and recent mammalian bones. Paleobiology, 6:341-351.

Hill, A.P. 1988. Early post-mortem damage to the remains of some contemporary east African mammals. In: A.K. Behrensmeyer \& A.P. Hill (eds.) Fossils in the making: vertebrate taphonomy and paleoecology, University of Chicago Press, p. 131-152.

Hill, C.; Sutherland, W.; Tierney, L. 1976. Caves of Wyoming. Laramie, Geological Survey of Wyoming, University of Wyoming Press, 230 p. (Bulletin 59).

Holanda, E.C. 2007. Os Tapiridae (Mammalia, Perissodactyla) do Pleistoceno superior do Estado de Rondônia, Brasil. Programa de Pós-graduação em Geociências, Universidade Federal do Rio Grande do Sul, Dissertação de Mestrado, 79 p.

Holten, B. \& Sterll, M. 2011. Peter Lund e as grutas com ossos em Lagoa Santa. $1^{\text {a }}$ ed. Belo Horizonte, UFMG, 335 p.

Holz, M. \& Barberena, M.C. 1989. A importância da tafonomia para o estudo de vertebrados fósseis. Acta Geológica Leopoldensia, 12:77-92.

Holz, M. \& Schultz, C.L. 1998: Taphonomy of the south Brazilian Triassic herpetofauna: fossilization mode and implications for morphological studies. Lethaia, 31:335-345. doi: 10.1111/j.15023931.1998.tb00523.x

Holz, M. \& Simões, M.G. 2002. Elementos Fundamentais de Tafonomia. Porto Alegre, UFRGS, $231 \mathrm{p}$.

Hsiou, A.S.; Santos, D.S.; Avilla, L.; Schubert, B.W. \& Winck, G.R. 2013. Dados preliminares sobre os lagartos e serpentes (Lepidosauria, Squamata) do Pleistoceno Final da região de Aurora do Tocantins, província espeleológica do grupo Bambuí, Tocantins, Brasil. In: CONGRESSO BRASILEIRO DE ESPELEOLOGIA, 32, 2013. Anais, Campinas, SBE, p. 427-431.

Hubbe, A. 2008. Contextualização taxonômica, tafonômica e morfométrica dos remanescentes ósseos da megamastofauna da Gruta Cuvieri (MG), um sítio paleontológico do Pleistoceno Tardio. Programa de Pós-graduação em Biociências, Universidade de São Paulo, Dissertação de Mestrado, 141 p.

Hubbe, A. \& Auler, A.S. 2012. A large Cervidae Holocene accumulation in Eastern Brazil: an example of extreme taphonomical control in a cave environment. International Journal of Speleology, 41:299-307. doi: 10.5038/1827806x.41.2.15

International Committee on Veterinary Gross Anatomical Nomenclature, 1983. Nomina Anatomica Veterinaria (3rd ed.) and Nomina Histologica $\left(2^{\text {nd }}\right.$ ed.) Nova Yorque, Ithaca, $60 \mathrm{p}$.

Kellner, A.W.A. \& Campos, D.A. 1999. Vertebrate paleontology in Brazil - a review. Episodes, 22:238-251.

Kohler, H.C. 1989. Geomorfologia cárstica na Região de Lagoa Santa - MG. Programa de Pós-graduação em Filosofia, Letras e Ciências Humanas, Universidade de São Paulo, Tese de Doutorado, 113 p.

Kohler, F. 1994. Geomorfologia cárstica. In: A.J.T. Guerra \& S.B. Cunha (eds.) Geomorfologia: uma atualização de bases e conceitos, Bertrand Brasil, p. 309-334.

Kos, A.M. 2003. Pre-burial taphonomic characterization of a vertebrate assemblage from a pitfall cave fossil deposit in southeastern Australia. Journal of Archaeological Science, 30:769-779. doi:10.1016/S0305-4403(02)00251-0

Kraemer, B.M. 2005. Aspectos ecomorfológicos indicadores de modalidades locomotoras e estratégias de forrageadora de xenartros Phyllophaga Owen, 1842 e Vermilingua Illiger, 1811 atuais e fósseis intertropicais brasileiros (Xenarthra, Pilosa). Programa de Pós-graduação em Zoologia, Pontifícia Universidade Católica de Minas Gerais, Dissertação de Mestrado, 100 p.

Krone, R. 1909. Estudo sobre as cavernas do Vale do Rio Ribeira. Arquivos do Museu Nacional do Rio de Janeiro, 15:139-166.

Langer, M.C.; Montefeltro, F.C.; Castro, M.C.; Marsola, J.C.A.; França, M.A.G.; Vila Nova, B.; Kerber, L. \& Rabello, F. 2013. Fósseis de Caiman da Gruta Ioiô, Bahia Brasil. In: CONGRESSO BRASILEIRO DE PALEONTOLOGIA, 23, 2013. Anais, Gramado, SBP, p. 239.

Lino, C.F.; Dias Neto, C.M.; Trajano, E.; Gusso, G.L.N.; Karmann I. \& Rodrigues R. 1979. Paleontologia das cavernas do Vale do Ribeira e Exploração I e Abismo do Fóssil (SP-145). Resultados parciais. In: SIMPÓSIO REGIONAL DE GEOLOGIA, 2, 1979. Atas, Rio Claro, SRG, p. 257-268.

Lund, P.W. 1836. Cavernas existentes no calcário do interior do Brasil, contendo algumas delas ossadas fósseis - Primeira memória. In: P.W. Lund \& C. Paula Couto (eds.) Memórias sobre a Paleontologia Brasileira, revistas e comentadas por Carlos de Paula Couto, Instituto Nacional do Livro, p. 67-106.

Lund, P.W. 1837. Segunda memória sobre a fauna das cavernas mamíferos. In: P.W. Lund \& C. Paula Couto (eds.) Memórias sobre a Paleontologia Brasileira, revistas e comentadas por Carlos de Paula Couto, Instituto Nacional do Livro, p. 131-206.

Lund, P.W. 1838. Terceira memória sobre a fauna das cavernas continuação dos mamíferos. In: P.W. Lund \& C. Paula Couto (eds.) Memórias sobre a Paleontologia Brasileira, revistas e comentadas por Carlos de Paula Couto, Instituto Nacional do Livro, p. 207-250.

Lund, P.W. 1841. Quarta memória sobre a fauna das cavernas. In: P.W. Lund \& C. Paula Couto (eds.) Memórias sobre a Paleontologia Brasileira, revistas e comentadas por Carlos de Paula Couto, Instituto Nacional do Livro, p. 317-377.

Lyman, R.L. 1994. Vertebrate taphonomy. $1^{\text {st }}$ ed. Cambridge, Cambridge University Press, 524 p. 
Mayer, E.L. 2011. Processos de formação de um depósito fossilifero em abismo na Gruta Cuvieri (MG): taxonomia, tafonomia e distribuição espacial de fósseis de mamíferos do Pleistoceno. Programa de Pós-graduação em Biociências, Universidade de São Paulo, Dissertação de Mestrado, 162 p.

Mayer, E.L. 2013. Pequenos mamíferos do Sumidouro do Sansão, Serra da Capivara, Piauí: resultados preliminares. In: CONGRESSO BRASILEIRO DE ESPELEOLOGIA, 32, 2013. Anais, Barreiras, SBE, p. 439-446.

MC Ambiental LTDA. 2012. Relatório de Valoração Espeleológica, Maciços Limeira, Escrivânia e Ingleses - Prudente de Morais, MG. Sandra Mineração Ltda. Relatório Interno. Belo Horizonte, $138 \mathrm{p}$.

Minas Gerais, 2005. Termo de referência para elaboração de estudos de impacto ambiental para atividades minerárias em áreas cársticas no Estado de Minas Gerais. Belo Horizonte, Fundação Estadual do Meio Ambiente, 28 p.

Missagia, R.V.; Dutra R.P.; Dantas, M.A.T.; Pêgo, F.B.; Raugust, T.; Delicio, M.P.; Silva, L.A. \& Renó, R. 2012. Registro fossilífero de mamíferos da caverna Toca Fria, Iuiú, Bahia, Brasil. In: PALEO 2012 MINAS GERAIS, 1, 2012. Boletim de Resumos, Belo Horizonte, IGC/UFMG, p. 7.

Munro, N.D. \& Bar-Oz, G. 2004. Debating issues of equifinality in ugulate skeletal part studies. Journal of Taphonomy, 2:1-13

Nascimento, E.R. 2008. Os Xenarthras Pilosa (Megatheriidae), Notoungulata (Toxodontidae) e Proboscidea (Gomphotheriidae) da Formação Rio Madeira, Pleistoceno Superior, Estado de Rondônia, Brasil. Programa de Pós-Graduação em Geociências, Universidade Federal do Rio Grande do Sul, Dissertação de Mestrado, $111 \mathrm{p}$.

Paula Couto, C. 1952. Fossil mammals from the beginning of the Cenozoic in Brazil - Condylarthra, Litopterna, Xenungulata and Astrapotheria. Bulletin of the American Museum of Natural History, 99:356-394.

Paula Couto, C. 1958. Notas à margem de uma expedição científica a Minas Gerais. Kriterion - Revista da Faculdade de Filosofia da $U M G, 11: 401-423$.

Paula Couto, C. 1979. Tratado de Paleomastozoologia. Rio de Janeiro, Academia Brasileira de Ciências, 590 p.

Perini, F.A.; Guedes, P.G.; Neto, C.R.M.; Fracasso, M.P.A.; Cardoso, K.B.; Duhá, D. \& Salles, L.O. 2008. Artiodactyla, Litopterna, Notoungulata e Perissodactyla do Quaternário da Serra da Bodoquena (Mato Grosso do Sul). In: SIMPÓSIO BRASILEIRO DE PALEONTOLOGIA DE VERTEBRADOS, 4, 2008. Boletim de Resumos, Ribeirão Preto, USP, p. 158-159.

Perônico, C. \& Araújo, A.C.S. 2002. Diversidade faunística baseada em escavação tafonomicamente orientada de material sub-recente preservado em caverna da região cárstica de Lagoa Santa, Minas Gerais. Arquivos do Museu Nacional, 6:195-198.

Piló, L.B. 1998. Morfologia cárstica e materiais constituintes: dinâmica e evolução da depressão poligonal Macacos-Baú, Carste de Lagoa Santa, MG. Programa de Pós-Graduação em Geografia Física, Universidade de São Paulo, Tese de Doutorado, $250 \mathrm{p}$.

Piló, L.B.; Auler, A.S.; Neves, W.A.; Wang, X.; Cheng, H. \& Edwards, R.L. 2004. Revisitando a Lapa do Sumidouro: marco paleo-antropológico do Quaternário americano. Revista Brasileira de Paleontologia, 7:337-348.

Porpino, K.O.; Santos, M.F.C.F. \& Bergqvist, L.P. 2004. Registros de mamíferos fósseis no Lajedo de Soledade, Apodi, Rio Grande do Norte, Brasil. Revista Brasileira de Paleontologia, 7:349-358.
Riff, D.; Avilla, L.S.; Mothé, D. \& Abranches, C.T.S. 2008. Novos registros de megafauna de mamíferos para o sertão do sudoeste baiano. In: SIMPÓSIO BRASILEIRO DE PALEONTOLOGIA DE VERTEBRADOS, 4, 2008. Boletim de Resumos, Ribeirão Preto, USP, p. 177-178.

Rodrigues, P.H.; Ferigolo, J. \& Ribeiro, A.M. 2003. Roedores pleistocênicos da planície costeira do Rio Grande do Sul, Brasil. In: CONGRESSO BRASILEIRO DE PALEONTOLOGIA, 18, 2003. Anais, Brasília, SBP, p. 235.

Salles, L.O.; Cartelle, C.; Guedes, P.G.; Boggiani, P.C.; Janoo, A. \& Russo, C.A.M. 2006. Quaternary mammals from Serra da Bodoquena, Mato Grosso do Sul, Brazil. Boletim do Museu Nacional, 521:1-12.

Sedor, F.A.; Born, P.A. \& Santos, F.M.S. 2004. Fósseis pleistocênicos de Scelidodon (Mylodontidae) e Tapirus (Tapiridae) em cavernas paranaenses (PR, sul do Brasil). Acta Biológica Paranaense, 33:121-128.

Sedor, F.A. \& Silva, D.D. 2006. Mastofauna pleistocênica do Estado do Paraná: estado atual do conhecimento. Porto Alegre, Boletim Informativo da Sociedade Brasileira de Paleontologia, p. 46 (Paleontologia em Destaque, 21).

Shipman, P. 1993. Life history of a fossil: an introduction to taphonomy and paleoecology. $2^{\text {nd }}$ ed. Cambridge MA, Harvard University Press, $222 \mathrm{p}$.

Silva, J.L.L. 2001. Tafonomia em mamíferos pleistocênicos: caso da planície colúvio - aluvionar de Maravilha - AL. Programa de Pós-Graduação em Geociências, Universidade Federal de Pernambuco, Dissertação de Mestrado, 99 p.

Simms, M.J. 1994. Emplacement and preservation of vertebrates in caves and fissures. Zoological Journal of the Linnean Society, 112:261-283. doi: 10.1111/j.1096-3642.1994.tb00320.x

Sinibaldi, R.W. 2010. What your fossils can tell you: vertebrate morphology, pathology and cultural modification. Gainesville, University Press of Florida, $370 \mathrm{p}$.

Souza Cunha, F.L. 1960. Sobre o Hippidion da Lapa Mortuária de Confins, Lagoa Santa, Minas Gerais: estudos geopaleontológicos baseados na Lapa mortuária e na coleção "Padberg-Drenkpol" do Museu Nacional. Programa de PósGraduação em Filosofia Ciências e Letras, Universidade do Rio de Janeiro, Tese de Concurso de Livre Docência da cadeira de Geologia e Paleontologia, 55 p.

Souza Cunha, F.L. 1964. O homem de Lagoa Santa e o Pleistoceno Sul Americano. Revista Brasileira de Arqueologia, 1:30-41.

Suguio, K. 2010. Geologia do Quaternário e mudanças ambientais. $2^{\mathrm{a}}$ ed. São Paulo, Oficina de Textos, 408 p.

Teixeira, R. 1980. Grutas da Região Cárstica de Lagoa Santa: Lapinha. Belo Horizonte, Edições Júpiter, 45 p.

Vasconcelos, A.G.; Vilaboim, L.S. \& Kraemer, B.M. 2008. New occurrence of Pleistocenic mammals in Chapada Diamantina, Brazil. A paleoenvironmental studies collaboration. In: CONGRESSO LATINOAMERICANO DE PALEONTOLOGIA DE VERTEBRADOS, 3, 2008. Anais, Neuquén, p. 258.

Vasconcelos, A.G.; Mayer, K.E.B. \& Campello, M.S. 2012. Novos depósitos fossilíferos nos maciços calcários Escrivânia, Limeira e Ingleses em Prudente de Morais, MG. In: PALEO 2012 Minas Gerais, 1, 2012. Boletim de Resumos, Belo Horizonte, IGC/ UFMG, p. 11.

Walter, H. 1943. Sobre alguns dos últimos achados de mastodontes na região de Pedro Leopoldo. Anais da Academia Mineira de Ciências de Minas Gerais, 1:3-6.

Wang, X. \& Martin, L. 1993. Natural trap cave. National Geographic Research \& Exploration, 9:422-435. 
Winge, H. 1888. Jordfundne og nulevende Gnavere (Rodentia) fra Lagoa Santa, Minas Geraes, Brasilien: Med Udsigt over Gnavernes indbyrdes Slægtskab. E Museo Lundii, 3:1-178.

Winge, H. 1906. Jordfundne og nulevende Hovdyr (Ungulata) fra Lagoa Santa, Minas Geraes, Brasilien: Med Udsigt over Hovdyrenes indbyrdes Slægtskab. E Museo Lundii, 3:1-239.

Ximenes, C.L. 2009. Tanques fossilíferos de Itapipoca, CE bebedouros e cemitérios de megafauna pré-histórica. In: M.
Winge; C. Schobbenhaus; C.R.G. Souza; A.C.S. Fernandes; M. Berbert-Born \& E.T. Queiroz (eds.) Sitios Geológicos e Paleontológicos do Brasil, CPRM, p. 465-478.

Received in May, 2014; accepted in December, 2014. 
Apêndice 1. Lista taxonômica do material estudado.

Appendix 1. Taxonomic list of the studied material.

Ordem XENARTHRA Cope, 1889

Família Mylodontidae Gill, 1872

Material estudado. Fragmento de molariforme (IGC/0586) (Figura 7A).

Família Dasypodidae Gray, 1821

Gênero Dasypus Linnaeus, 1758

Dasypus novemcinctus Linnaeus, 1758

Material estudado. Dois osteodermos (IGC/0587 e IGC/0588) (Figuras 7B,C).

Ordem Rodentia Bowdich, 1821

Família Cuniculidae Miller \& Gidley, 1918

Gênero Cuniculus Brisson, 1762

Cuniculus major Lund, 1837

Material estudado. Mandíbula (IGC/0579), úmero direito (IGC/0580), fragmento de ulna esquerda (IGC/0581), porção distal do rádio direito (IGC/0582), metapodial (IGC/0583), fêmur esquerdo (IGC/0584), calcâneo direito (IGC/0585) (Figura 8).

Ordem Lagomorpha Brandt, 1885

Material estudado. Fragmentos de fêmur esquerdo (IGC/0592 e IGC/0593) (Figuras 7D,E).

Ordem Carnivora Bowdich, 1821

Família Canidae Fischer von Waldheim, 1817

Gênero Speothos Lund, 1839

Speothos sp.

Material estudado. Dois fêmures direitos (IGC/0589 e IGC/0590) (Figuras 7F,H).

Família Mustelidae Swainson, 1835

Gênero Eira Smith, 1842

Eira barbara Linnaeus, 1758

Material estudado. Ramo mandibular esquerdo (IGC/0591) (Figura 7G).

Ordem Artiodactyla Owen, 1848

Família Tayassuidae Palmer, 1897

Gênero Tayassu Fischer de Waldheim, 1814

Tayassu pecari (Link, 1795)

Material estudado. Fragmento de arco zigomático (IGC/0555), fragmento de mandíbula (IGC/0554), cinco fragmentos de costela (IGC/0556, IGC/0557, IGC/0558, IGC/0559, IGC/0560), fragmento de úmero (IGC/0561), fragmentos de ulna/rádio (IGC/0562 e IGC/0563), unciforme (IGC/0564), metacarpal II (IGC/0565), metacarpal V (IGC/0566), metapodial (IGC/0567), quatro falanges médias (IGC/0568, IGC/0569, IGC/0570, IGC/0571), dois fragmentos de cintura pélvica (IGC/0572 e IGC/0573), fragmentos e epífise de fêmur (IGC/0574, IGC/0575 e IGC /0576), tíbia (IGC/0577) e metatarsal IV (IGC/0578) (Figura 9). 